\title{
Investigating the Impact of Standards-Based Interoperability for Design to Manufacturing and Quality in the Supply Chain
}

\author{
Kevin Fischer \\ Rockwell Collins \\ Phil Rosche \\ Advanced Collaboration Consulting Resources \\ Asa Trainer \\ International TechneGroup Incorporated
}

This publication is available free of charge from:

http:// dx.doi.org/10.6028/NIST.GCR.15-1009 
NIST GCR 15-1009

\title{
Investigating the Impact of Standards-Based Interoperability for Design to Manufacturing and Quality in the Supply Chain
}

\author{
Prepared for \\ U.S. Department of Commerce \\ Engineering Laboratory \\ National Institute of Standards and Technology \\ Gaithersburg, MD 20899 \\ Kevin Fischer \\ By \\ Rockwell Collins \\ Phil Rosche \\ Advanced Collaboration Consulting Resources
}

Asa Trainer

International TechneGroup Incorporated

This publication is available free of charge from:

http:// dx.doi.org/10.6028/NIST.GCR.15-1009

December 2016

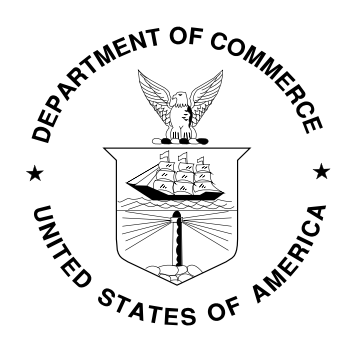

U.S. Department of Commerce Penny Pritzker, Secretary

National Institute of Standards and Technology Willie May, Under Secretary of Commerce for Standards and Technology and Director 


\section{Disclaimers}

This report was prepared for the Engineering Laboratory of the National Institute of Standards and Technology (NIST) under the following cooperative agreement:

- 70NANB14H314, International TechneGroup Incorporated, "Investigating the Impact of Standards-Based Interoperability for Design to Manufacturing and Quality in the Supply Chain"

Any opinions, findings, conclusions, or recommendations expressed in this publication do not necessarily reflect the views of NIST. Additionally, neither NIST nor any of its employees make any warranty, expressed or implied, nor assume any legal liability or responsibility for the accuracy, completeness, or usefulness of any information, product, or process included in this publication.

This paper may identify certain commercial systems. Such identification does not imply recommendation or endorsement by NIST. Nor does it imply that the products identified are necessarily the best available for the purpose. 


\section{Table of Contents}

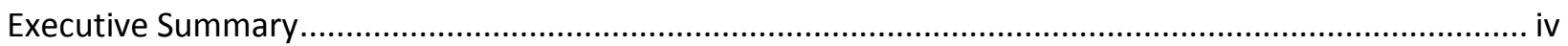

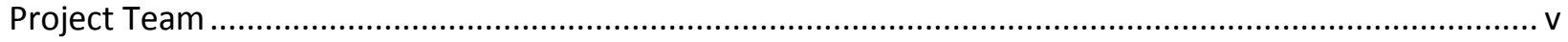

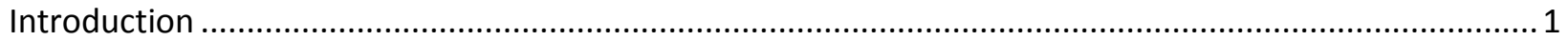

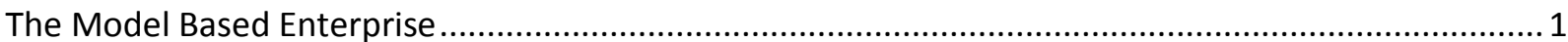

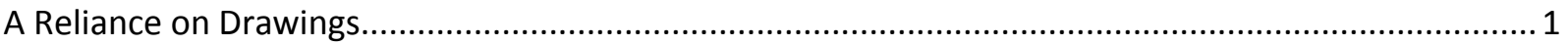

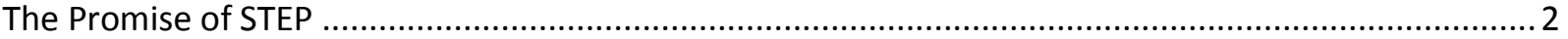

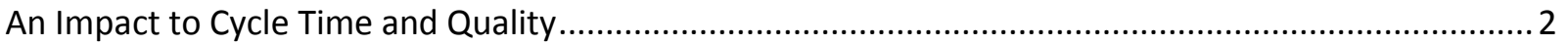

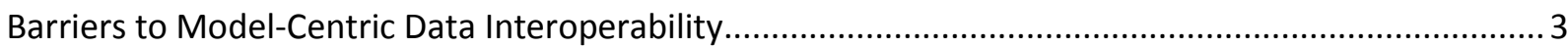

Opportunity for a Standards-Based Solution ..................................................................................

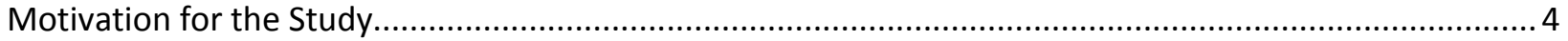

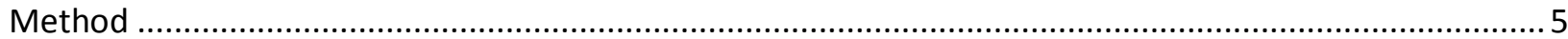

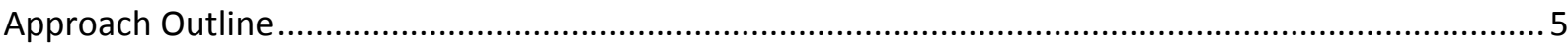

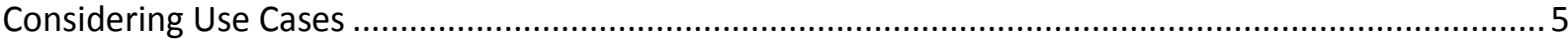

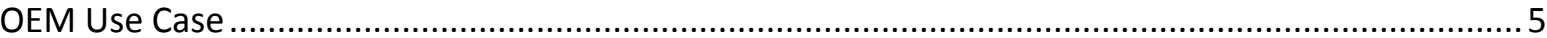

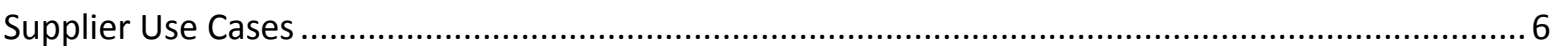

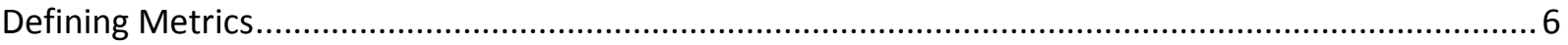

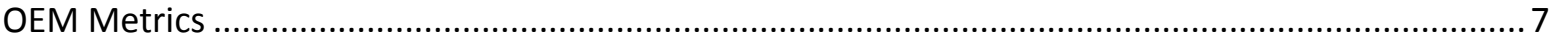

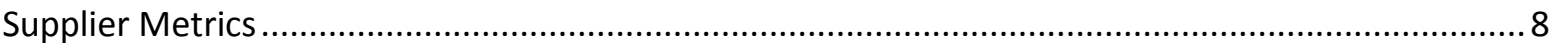

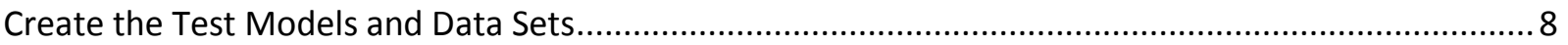

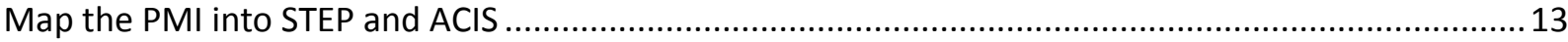

Demonstrate Standards-Based Interoperability .............................................................................. 14

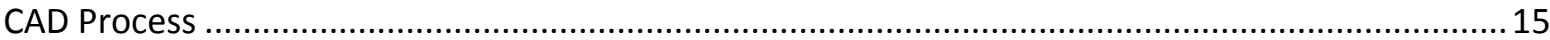

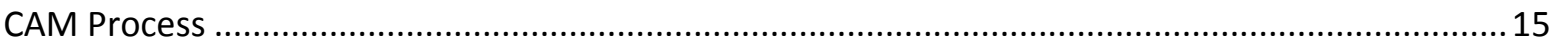

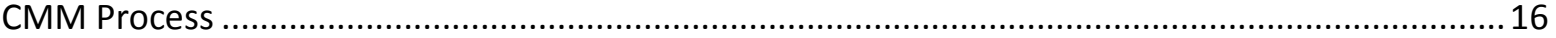

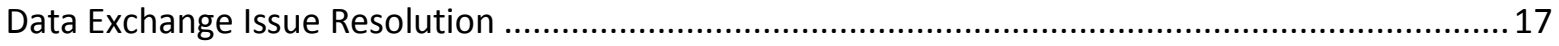

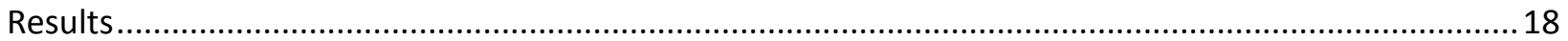

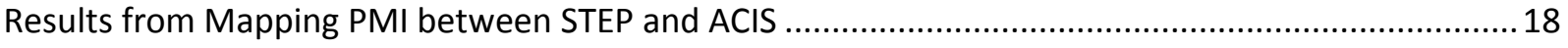

Results from Embedded PMI Data Exchange................................................................................... 19

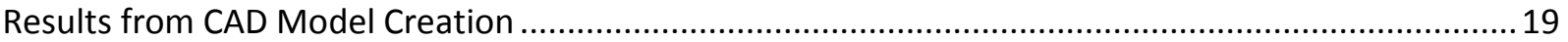


Investigating the Impact of Standards-Based Interoperability for Design to Manufacturing and Quality

Results from CAM Model Creation

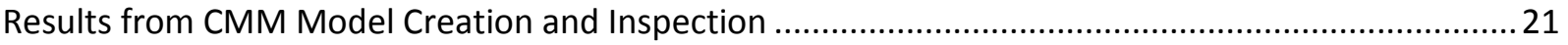

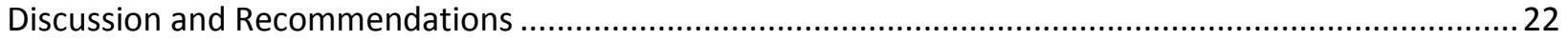

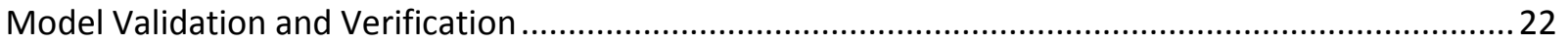

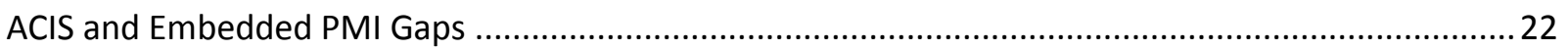

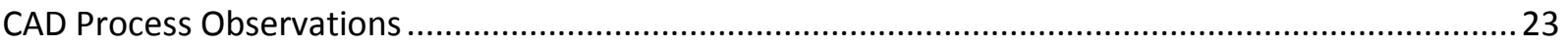

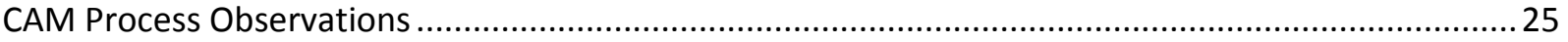

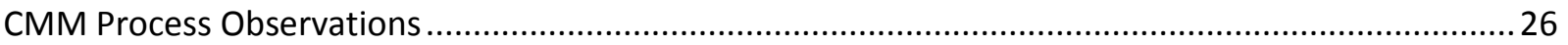

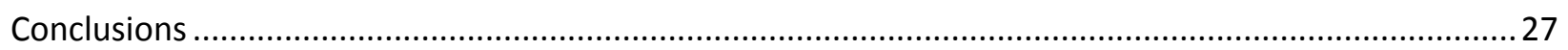

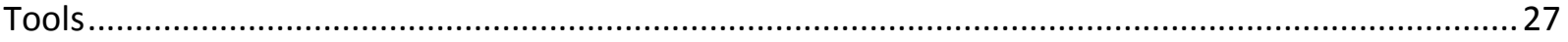

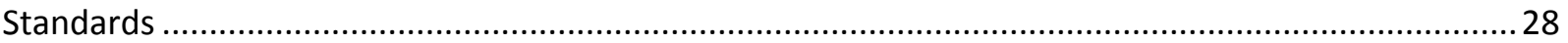

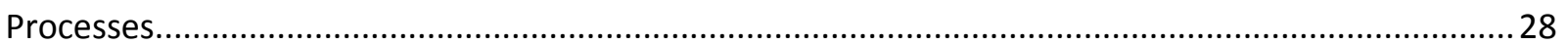

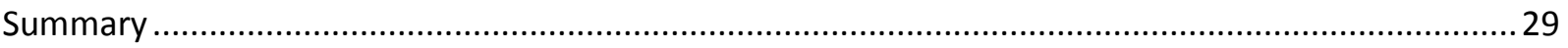

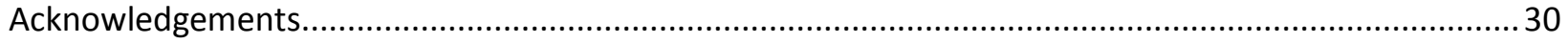

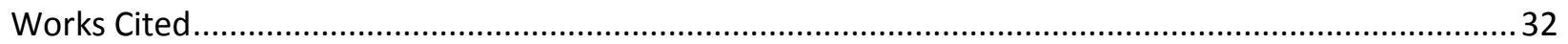

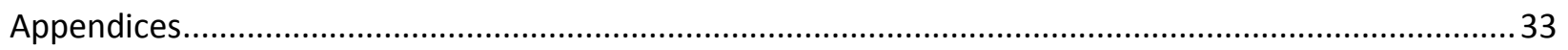

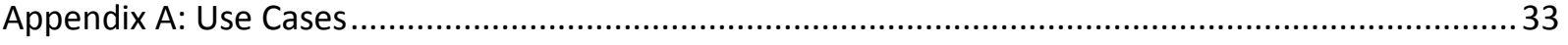

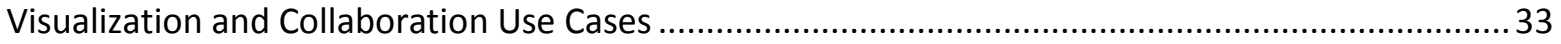

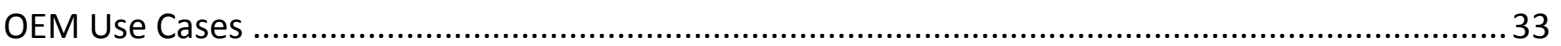

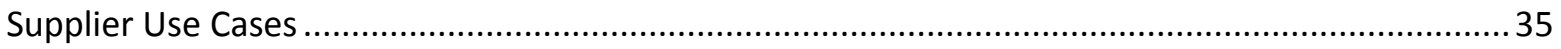

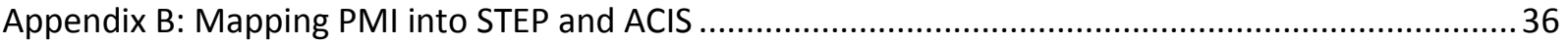

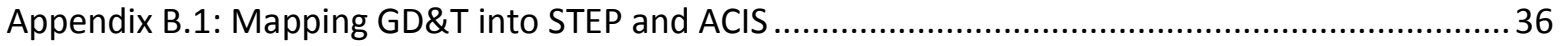

Appendix B.2: Mapping Other MBD-related Items into STEP and ACIS .......................................... 42

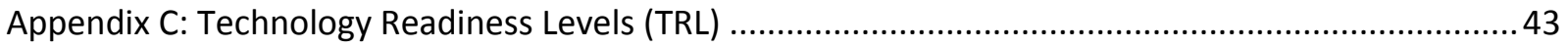


Investigating the Impact of Standards-Based Interoperability for Design to Manufacturing and Quality

\section{Executive Summary}

To achieve the industry vision of a Model-Based Enterprise (MBE), the MBE strategy must include model-centric data interoperability for design to manufacturing and quality in the supply chain. Even though there has been a move in industry to become model-centric, today there is still significant manual intervention in the supply chain to go from product design to manufacturing and quality inspection. The ISO 10303 Standard for the Exchange of Product Model Data (STEP) data standard can minimize much of the manual intervention. The majority of STEP implementations have been primarily focused on CAD-to-CAD and long-term data archival. Significant opportunity exists for STEP-based CADto-CAM and CAD-to-CMM data exchange.

The vision for this project was developed following a survey of small and medium enterprise (SME) suppliers. Despite being in the digital age, a large percentage of SME suppliers still receive OEM designs as full-detail-2-dimensional (2D) drawings or as a combination of 3-dimensional (3D)-shape-geometry models plus 2D drawings containing the product and manufacturing information (PMI). A large percentage of suppliers must either completely remodel the part or manually add the PMI to the imported shape-geometry model. Much of the CAD industry has implemented STEP AP242 with embedded PMI, reducing the need for drawings. The same degree of implementation has not occurred in the CAM and CMM industries. This project demonstrates the value of improved CAD-to-CAM and CAD-to-CMM data interoperability using STEP AP242 with embedded PMI.

This project was developed to investigate high-payback use cases in the supply chain and identify opportunities of model-centric standards-based data exchange to:

- Eliminate or reduce significantly the need to re-create downstream models,

- Reduce cycle time and cost,

- Reduce the risk of introducing downstream errors,

- Increase part yield, and

- Produce higher quality parts.

The project team consisted of an OEM, supplier, system integrators, as well as CAM and CMM system providers. The NIST Engineering Laboratory provided direction and guidance for this standards-based data exchange demonstration. Three data exchange scenarios were compared in the investigation:

- Full-detail-2D drawing

- 3D-shape-geometry model and a 2D drawing containing the PMI

- 3D model with embedded PMI

Metrics were established to assess the cycle time for CAD, CAM, and CMM model creation and the ease of data interoperability in each data exchange scenario. The results were compared and observations shared by the project team. There was clear cycle time advantage demonstrated with the use of a 3D model with embedded PMI for CAD-to-CMM data interoperability. Gaps were identified in tools, standards and interfaces, PMI-feature coverage, modeling knowledge, and best practices. 
Investigating the Impact of Standards-Based Interoperability for Design to Manufacturing and Quality

This project demonstrates the benefits of standards-based product-data interoperability in the supply chain for CAD-to-CAM and CAD-to-CMM. It also identifies gaps to be addressed to enable industry to achieve its MBE vision of becoming model-centric. This project can help industry push for commercialization of the demonstrated capability and achievement of the MBE vision.

\section{Project Team}

\section{Project Coordination}

Phil Rosche, Advanced Collaboration Consulting Resources

Asa Trainer, International TechneGroup Incorporated

OEM

Kevin Fischer, Rockwell Collins

Tom Matuska, Rockwell Collins

Jesse Pisarik, Rockwell Collins

Scott Wegener, Rockwell Collins

Supplier

Derrick Hess, Geater Machining \& Manufacturing

Greg Sondag, Geater Machining \& Manufacturing

System Integrators

Guillaume Blanchard, CT CoreTechnologie

David Selliman, CT CoreTechnologie

Gauthier Wahu, CT CoreTechnologie

Ed Paff, International TechneGroup Incorporated

\section{CAM System}

Pete Rimkus, CNC Software, Inc.

CMM System

Larry Maggiano, Mitutoyo America

Research Advisors

Allison Barnard Feeney, National Institute of Standards and Technology

Thomas Hedberg, Jr., National Institute of Standards and Technology 
Investigating the Impact of Standards-Based Interoperability for Design to Manufacturing and Quality

\section{Introduction}

The challenge: Given industry's vision of $M B E$, why is model-centric data interoperability not more prevalent for design to manufacturing and quality inspection?

\section{The Model Based Enterprise}

To achieve the industry vision of the model-based enterprise (MBE), the MBE strategy must include model-centric data interoperability for design to manufacturing and quality in the supply chain. The model-based definition (MBD) is created by the OEM using computer-aided-design (CAD) tools. This information is then shared with the supplier so that they can manufacture and inspect the physical parts. Much of the supply base consists of small and medium enterprise (SME) manufacturers. Today, almost all suppliers use computer-aided-manufacturing (CAM) and coordinate-measuring-machine (CMM) models respectively for these tasks. Traditionally, design data is provided by the OEM to supplier in the form of full-detail-2-dimensional (2D) drawings. More recently the data has also included a 3-dimensional (3D)-shape-geometry model. This shape-geometry model is often provided in a standards-based format, STEP AP203 is most prevalent. In addition to shape-geometry, the CAM and CMM processes require product and manufacturing information (PMI) to fabricate and inspect the part.

\section{A Reliance on Drawings}

Model-based exchange has primarily focused on CAD-to-CAD data interoperability and long term data archival. Even with the drive for industry to become increasingly model-centric, there is still significant manual intervention when going from OEM to supplier with product design for manufacturing and quality inspection. In part, this is due to the fact that the STEP AP203 model provides only shape geometry and does not contain the PMI necessary for CAM and CMM models and machine programs.

Despite the industry MBE vision to become model-centric and the model-based hype from major CAD suppliers, there is still a reliance on $2 \mathrm{D}$ drawings. A survey ${ }^{1}$ of SME suppliers shows that many of those surveyed still receive design data from their OEM customer in the form of full-detail-2D drawings.

Another large group receives a 3D-shape-geometry model combined with a 2D drawing containing the PMI. Only a small percentage of the SME manufacturers receive just a 3D model with embedded PMI. The design to manufacturing process is still very much drawing-centric. The very few data exchanges that are model-centric with embedded PMI use proprietary, not standards-based models. ${ }^{2}$

\footnotetext{
${ }^{1}$ Hartman, N., Fischer, K., \& Rosche, P. (May 21-23, 2012). Successfully Engaging Small and Medium Enterprises. $3 D$ Collaboration and Interoperability Congress. Englewood, CO.

${ }^{2}$ NIST MEP. (November 22, 2009). Phase One Final Report - Assessment of Supplier Capabilities to Operate in a Model-Based Enterprise Environment.
} 
Investigating the Impact of Standards-Based Interoperability for Design to Manufacturing and Quality

The Promise of STEP

Development of ISO 10303 Standard for the Exchange of Product Model Data (STEP) started in 1984. Its objective is to provide a mechanism that is capable of describing product data throughout the life cycle of a product, independent from any particular system. The nature of this description makes it suitable not only for neutral file exchange, but also as a basis for implementing and sharing product databases and archiving. ${ }^{3}$

STEP is developed with a series of integrated data models known as application protocols (AP's). There are dozens of STEP AP's, which can be roughly grouped into the three main areas design, manufacturing and life cycle support.

Today STEP AP203 Configuration Controlled 3D Design is still one of the most important parts of ISO 10303 and is supported by many CAD systems for import and export. According to another survey of SME suppliers, STEP AP203 is the most commonly used format for CAD-to-CAD data interoperability. ${ }^{4}$ But, the STEP AP203 model contains only shape geometry, and not the PMI necessary for downstream processes.

In December 2014 ISO published the first edition of a new major application protocol, STEP AP242 Managed Model Based 3D Engineering, which combined and replaced the following previous AP's in an upward compatible way:

- AP201 Explicit Draughting (simple 2D drawing geometry related to a product with no association and no assembly hierarchy)

- AP202 Associative Draughting (2D/3D drawing with association but no product structure)

- AP203 Configuration Controlled 3D Designs of Mechanical Parts and Assemblies

- AP204 Mechanical Design Using Boundary Representation

- AP214 Core Data for Automotive Mechanical Design Processes

In addition, STEP AP242 edition 1 contains extensions and significant updates for geometric dimensions and tolerances, kinematics, and tessellation. In other words, STEP AP242 offers standards-based models with embedded PMI - exactly what is needed for model-centric downstream CAM and CMM processes.

\section{An Impact to Cycle Time and Quality}

With the continued reliance on full-detail-2D drawings or even 3D-shape-geometry models, a significant amount of time is spent recreating the product model or adding PMI data to an existing shape model. This significantly affects cycle time. Furthermore, there is an increased risk of error from incorrect or missing data when recreating or enhancing models for downstream purpose, potentially affecting model and part quality.

\footnotetext{
${ }^{3}$ ISO/TC 184/SC 4. (1994, December 15). ISO 10303-1:1994. Industrial automation systems and integration -Product data representation and exchange -- Part 1: Overview and fundamental principles. International Organization for Standardization.

${ }^{4}$ Hartman, N., Fischer, K., \& Rosche, P. (May 21-23, 2012). Successfully Engaging Small and Medium Enterprises. $3 D$ Collaboration and Interoperability Congress. Englewood, CO.
} 
Investigating the Impact of Standards-Based Interoperability for Design to Manufacturing and Quality

In the survey mentioned earlier, SME manufacturers reported spending 2-4 hours adding PMI to a simple CAM model. They also reported spending twice that time, 4-8 hours, adding PMI to the CMM model. ${ }^{5}$ For more complex parts, an automotive engine block for example, the recreation of information for CAM and CMM might take weeks after receiving the OEM 2D drawing or 3D-shapegeometry model.

\section{Barriers to Model-Centric Data Interoperability}

Even with the introduction of STEP AP242, what keeps industry from moving toward the MBE vision? Especially, why can't industry achieve a vision that includes model-centric data interoperability when going from design to manufacturing and inspection across the supply chain? In the team's opinion, some of the barriers that keep industry from being more model-centric include:

- The 2D drawing is still considered the master versus the 3D model by many in industry.

- There is a significant learning curve to effectively embed PMI into a 3D CAD model.

- Many application program interfaces (API's) do not adequately support downstream processes due to lack of PMI.

- Major product lifecycle management (PLM) tool providers are concerned with losing market share due to easy data exchange through standards-based implementations.

- The CAM and CMM markets are distributed across many SME manufacturers and there is no significant aggregation of industry that drives CAM and CMM providers to implement standardsbased solutions.

\section{Opportunity for a Standards-Based Solution}

This project team composed of Aerospace and Defense industry members, along with several CAD, CAM, and $\mathrm{CMM}$ solution providers, discussed possible approaches to more effectively enable model-centric data exchange for CAD-to-CAM and CAD-to-CMM. Many CAM and CMM systems are based on the

The hypothesis: The ACIS and Parasolid modeling kernel can support CAD-to-CAM and CAD-to-CMM using STEP AP242 to exchange model-based definition with embedded PMI, reducing cycle time while improving model and part quality.

$\mathrm{ACIS}^{\circledR 6}$ modeling kernel and can already ingest model geometry and PMI data through their respective API's. They also ingest standards-based model geometry via STEP AP203. So, why can't they ingest standards-based PMI data now that STEP AP242 is available? Wouldn't this model-centric data exchange offer significant improvement in cycle time, model quality, and part quality? Can it be demonstrated that STEP AP242 minimizes much of the manual intervention and provides significant opportunity for standards-based CAD-to-CAM and CAD-to-CMM data interoperability? Lastly, could this

\footnotetext{
${ }^{5}$ Hartman, N., Fischer, K., \& Rosche, P. (May 21-23, 2012). Successfully Engaging Small and Medium Enterprises. $3 D$ Collaboration and Interoperability Congress. Englewood, CO.

${ }^{6} \mathrm{AClS}$ is a registered Trademark of Spatial Corporation.
} 
Investigating the Impact of Standards-Based Interoperability for Design to Manufacturing and Quality

demonstration plant a seed with the CAM and CMM industries to further commercialize STEP AP242 implementations?

This project will test the hypothesis that model-based data interoperability from CAD-to-CAM and CADto-CMM is practical and that there is significant value in implementation of STEP AP242 as a standardsbased solution. The project will answer the questions of feasibility and value through demonstration and measured results. It will also provide for discussion and recommendations based upon the findings and observations. Finally, the project will draw conclusions toward the pursuit of industry's vision of the Model Based Enterprise and the feasibility of standards-based model-centric data interoperability.

\section{Motivation for the Study}

With a supported hypothesis, the team believes this project will motivate industry in its drive to achieve the vision of the Model Based Enterprise. The goal of this project was to demonstrate the value of model-centric CAD-to-CAM and CAD-to-CMM data interoperability when using STEP AP242 with embedded PMI. The anticipated benefits from this standards-based approach between the systems and

The motivation: Demonstrate the value of model-centric CAD-to-CAM and CAD-to-CMM data interoperability using STEP AP242 with embedded PMI.

across the supply chain include:

- Eliminating or reducing significantly the need to re-create part models,

- Reducing cycle time and cost,

- Reducing the risk of introducing downstream errors,

- Increasing part yield, and

- Producing higher quality parts.

The technology developed by this project is extensible to include PMI-data items beyond those used in the project test models. The CAD, CAM, and CMM applications can successfully exchange more complex parts than the test models used in this project.

This project demonstrates the applications have achieved Technology Readiness Level (TRL) 6 and industry is pushing for further technology maturity. The current TRL scale runs from level 1 to 9 . TRL 1 , the least mature technology readiness level, is the state when basic research ideas are taking the first steps toward practical application. TRL 9 is the most mature technology readiness level and the product is in full production use. TRL 6 is the maturity level where a prototype capability is represented in a simulated operational environment. Organizations will typically begin to adopt technology as it achieves TRL 7 or higher. A full list of the TRL definitions is given in Appendix C.

Demonstrating the technology readiness for CAD-to-CAM and CAD-to-CMM data-interoperability provides motivation to commercialize tools that provide standards-based 3D models with embedded 
Investigating the Impact of Standards-Based Interoperability for Design to Manufacturing and Quality

PMI to the CAM and CMM industry. Likewise, the CAM and CMM tools providers should be motivated to commercialize the ability to receive and utilize the standards-based 3D models with embedded PMI.

As the identified gaps in current tools and standards are addressed to achieve this level of commercialization, and the process and skill gaps are overcome by industry users, the opportunity to improve efficiency and effectiveness across the product lifecycle will be provided in design, bidding and quoting, manufacturing, inspection, and collaboration across the supply chain.

\section{Method}

\section{Approach Outline}

To test the hypothesis, the following approach was used:

- Consider the use cases creating or utilizing CAD, CAM, and CMM data.

- Develop metrics to compare results of current versus future model-centric processes,

- Map model-based PMI requirements to STEP AP242, map STEP AP242 to ACIS geometric modeling kernel, and identify gaps that hinder broad solution deployment,

- Develop prototype software to demonstrate data interoperability between CAD, CAM, and CMM tools using standards-based STEP AP242 models with embedded PMI,

- Test the current and future model-centric processes using representative industry part designs,

- Validate the CAM and CMM models against the original CAD model for any data loss during transformation and any missing CAM or CMM information,

- Refine the test cases and software following an analysis of the initial results, and

- Collect and analyze the metrics data to determine benefits associated with the process change.

\section{Considering Use Cases}

Various product lifecycle use cases were investigated as the project team explored how the benefits described earlier might manifest across the product lifecycle. The use cases were organized into two categories: (1) use cases that affect the OEM and (2) use cases that affect the supplier. Ultimately, a partial set of the use cases (those best aligned to the scope of this project) were used to define the project metrics and demonstrate the differences between current-state and future-state processes. Below is a description of the use cases that define and affect the metrics for this project. Appendix $A$ includes the broader set of product lifecycle use cases discussed by the team, including those beyond the scope of this project.

\section{OEM Use Case}

\section{CAD Model Creation}

This use case centers on the creation or authoring of the CAD model. Traditionally, the 3D-shapegeometry model is created without embedded PMI. Once the shape-geometry model is generated, a drawing is created, and typically presented in 2D PDF format. It includes the PMI that is not part of the 3D-shape-geometry model. In the past, the 2D drawing was fully detailed and could be used by itself to 
Investigating the Impact of Standards-Based Interoperability for Design to Manufacturing and Quality manufacture the part. In more recent practice, a 3D-shape-geometry model and a 2D-partial-dimension drawing are required. The partial-dimension drawing contains only the PMI that is not embedded in the shape model. In the current-state scenarios either the full-detail drawing or the combination of the shape model and the partial-detail drawing is required for manufacturing processes. In the future-state process designers will create a 3D model with embedded PMI such that the model will completely support the manufacturing and inspection processes.

\section{CAD Validation and Verification}

This use case involves validation and verification of design intent, model correctness, and producibility. Persons with the appropriate subject matter expertise review the design at points in the lifecycle to determine that it meets design intent, follows best drawing or modeling practices, and meets desirable producibility expectations. The traditional way of visually inspecting drawings, and more recently models, does not always work. With model-based design it is not possible for a human (visual) inspection of the model to detect all issues. As a result, rules-based systems have been introduced to automate the process, especially for model and producibility analysis. In addition to analyzing the construct of a unique model, it is also necessary to compare two different models when data exchange occurs. This ensures the original design intent is correctly transferred to the downstream model, such as when a model is exchanged between design and manufacturing or inspection.

\section{Supplier Use Cases}

\section{CAM Model Creation}

The CAM-programming use case focuses on the import of a STEP AP203 model for the shape-geometry. The 2D drawing is referenced for the PMI not embedded in the model. In addition, the manufacturing specifications that are referenced in the drawing are also reviewed to determine additional machine programming and secondary operations.

\section{CMM Model Creation}

The CMM-model use case utilizes the 2D drawing and the STEP AP203 model to create the CMM model. All the $\mathrm{PMI}$ is manually entered into the $\mathrm{CMM}$ application. The demonstrated future-state directly imports the embedded PMI from a STEP AP242 model.

\section{CMM Inspection}

The CMM-inspection use case requires a significantly manual and time-consuming process to generate the first article inspection report. The inspector must review the CMM results and manually input the information into a spreadsheet that conforms to AS9102 FAI report standards.

\section{Defining Metrics}

The project team defined a set of metrics to understand the impact of more comprehensive modelbased interoperability. The metrics for the use cases provide a way to compare the current state and future state of part design, manufacture, and inspection. The metrics support the investigation of the benefits and challenges of data interoperability when using 3D models with embedded PMI for downstream purpose. These metrics include cycle time, model quality, part quality, and cost. Table 1 provides the target metrics for each use case. 
Investigating the Impact of Standards-Based Interoperability for Design to Manufacturing and Quality

Table 1: Project use case and defined metrics

\begin{tabular}{|l|c|c|c|c|}
\hline \multirow{2}{*}{ Use Cases } & \multicolumn{3}{c|}{ Metrics } \\
\cline { 2 - 5 } & $\begin{array}{c}\text { Cycle } \\
\text { Time }\end{array}$ & $\begin{array}{c}\text { Model } \\
\text { Quality }\end{array}$ & $\begin{array}{c}\text { Part } \\
\text { Quality }\end{array}$ & Cost \\
\hline \multirow{2}{*}{ at OEM } & & & & \\
\hline CAD model creation & $\mathrm{X}$ & $\mathrm{X}$ & & \\
\hline CAD validation and verification (design intent; model correctness; producibility) & $\mathrm{X}$ & $\mathrm{X}$ & & $\mathrm{X}$ \\
\hline at Supplier & & & & \\
\hline CAM programming & $\mathrm{X}$ & $\mathrm{X}$ & & \\
\hline CMM programming & $\mathrm{X}$ & $\mathrm{X}$ & & \\
\hline CMM inspection & $\mathrm{X}$ & & $\mathrm{X}$ & \\
\hline
\end{tabular}

Cycle Time Metrics

The cycle-time metric measures the time to complete each use-case step and is a key to the project investigation. The use cases were divided into a discrete set of steps for the operator to record the time it took to complete the step.

Model Quality Metrics

Model quality includes completeness as well as comprehensiveness. One metric compares the number of PMI elements found in the models. The PMI data types are broken down by dimension, tolerance, datum feature, and notes (with no semantic data). This metric provides visibility into model quality and how well the data is translated from native CAD to STEP AP242, to ACIS, and ultimately to the CAM and $\mathrm{CMM}$ models. As each data model exchange occurs, the PMI elements for the models were compared for completeness and comprehensiveness.

\section{Part Quality Metrics}

Part quality metrics indicate when the part does not match the design intent. They are found through $\mathrm{CMM}$ inspection and documented in the FAI report. The metrics indicate the clarity of information, report generation, etc.

\section{Cost Metrics}

While cost is a derivative metric for many use cases, the actual base metric in most of those cases is the cycle-time to complete the process. Thus, cycle-time is the metric of focus. Cost is, however, the base metric directly affected in part validation, procurement and bidding processes. Cost is identified as a metric with direct impact on the accuracy of the bidding process. It also comes into play during a producibility reviews when considering design aspects that actually drive an increase or decrease in part fabrication costs.

\section{OEM Metrics}

The OEM metrics captured for part design include CAD modeling and validation as shown in Table 2. 
Investigating the Impact of Standards-Based Interoperability for Design to Manufacturing and Quality

Table 2: OEM metrics

\begin{tabular}{|l|l|l|}
\hline OEM Process & Current-State Process (Metrics) & Future-State Process (Metrics) \\
\hline CAD model creation & $\begin{array}{l}\text { Create geometry model and PMI drawing } \\
\text { (cycle time, model quality) }\end{array}$ & $\begin{array}{l}\text { Create fully constrained model with } \\
\text { embedded PMI (cycle time, model quality) }\end{array}$ \\
\hline CAD model validation & $\begin{array}{l}\text { Semi-manual validation (cycle time, model } \\
\text { quality, cost) }\end{array}$ & $\begin{array}{l}\text { Automated validation (cycle time, model } \\
\text { quality, cost) }\end{array}$ \\
\hline
\end{tabular}

In particular, cycle time metrics were captured during the creation of the 3D model, 2D drawing, and embedded PMI. For this project, metrics were also captured and observations recorded for model issue resolution and designer education with regard to embedded PMI practices. Lastly, metrics were captured for the time required to understand and resolve issues discovered about 3D models with embedded PMI as the data was imported into the CMM system.

\section{Supplier Metrics}

The supplier metrics for part manufacture and inspection involves CAM and CMM programming, machining, and inspection as shown in Table 3.

Table 3: Supplier metrics

\begin{tabular}{|l|l|l|}
\hline Supplier Process & Current-State Process (Metrics) & Future-State Process (Metrics) \\
\hline CAM programming & $\begin{array}{l}\text { Import part shape into CAM, manual } \\
\text { addition of PMI (cycle time, model quality) }\end{array}$ & $\begin{array}{l}\text { Import part shape and embedded PMI into } \\
\text { CAM (cycle time, model quality) }\end{array}$ \\
\hline CMM programming (input) & $\begin{array}{l}\text { Import part shape into CMM, manual } \\
\text { addition of PMI (cycle time, model quality) }\end{array}$ & $\begin{array}{l}\text { Import part shape and embedded PMI into } \\
\text { CMM (cycle time, model quality) }\end{array}$ \\
\hline CMM Inspection (output) & $\begin{array}{l}\text { Manually create inspection programming } \\
\text { (cycle time, part quality) }\end{array}$ & $\begin{array}{l}\text { Automate CMM inspection programming } \\
\text { (cycle time, part quality) }\end{array}$ \\
\hline
\end{tabular}

The metrics captured for part manufacture includes cycle-time to import the shape-geometry data into the CAM system. The current-state process also captured the metrics for the manual addition of PMI, while the future-state process used embedded PMI directly from the 3D-model import.

The metrics captured for part inspection includes cycle-time to import the shape-geometry data into the $\mathrm{CMM}$ system. The current-state process also captured the metrics for the manual addition of PMI, while the future-state process used embedded PMI directly from the 3D-model import. Metrics and insight were captured during the learning curve and issue resolution for importing embedded-PMI models into the CMM system.

\section{Create the Test Models and Data Sets}

The project team reviewed five part designs submitted by Rockwell Collins as candidates for the test models. The team selected two of the parts as the test cases for this project. These were based upon the model features and also considered how each part would be machined and inspected given the geometric dimension and tolerance (GD\&T) callouts. Furthermore, the team added new features to the models to test additional machining and inspection criteria. 
Investigating the Impact of Standards-Based Interoperability for Design to Manufacturing and Quality

The first part chosen was a rolled standoff shown in Figure 1. The design was altered to create a generic part using industry GD\&T practices. Modifications were made to the part length. There were no additional features added to this part.

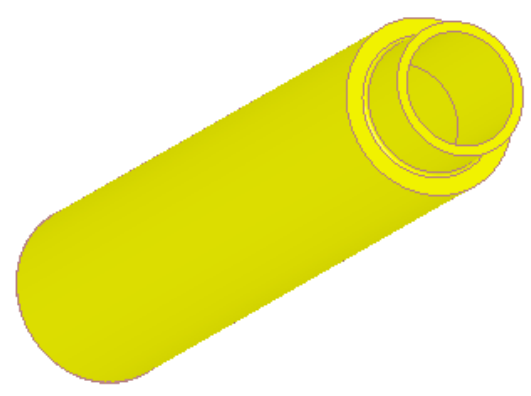

Figure 1: Rolled Standoff

The second part chosen was a heat sink shown in Figure 2. The design was altered to create a generic part using industry GD\&T practices. The heat-sink-fin feature was changed to incorporate a chamfer on one end. A heat-sink-pin array with a spherical radius on each pin tip was added near the fins. There were standoffs, bosses, and a flatness callout added to the bottom side to drive additional machining and inspection elements. Material attributes were added to the models to support downstream system input requirements. These attributes included the thermal expansion coefficient, thermal expansion coefficient units, and material name.

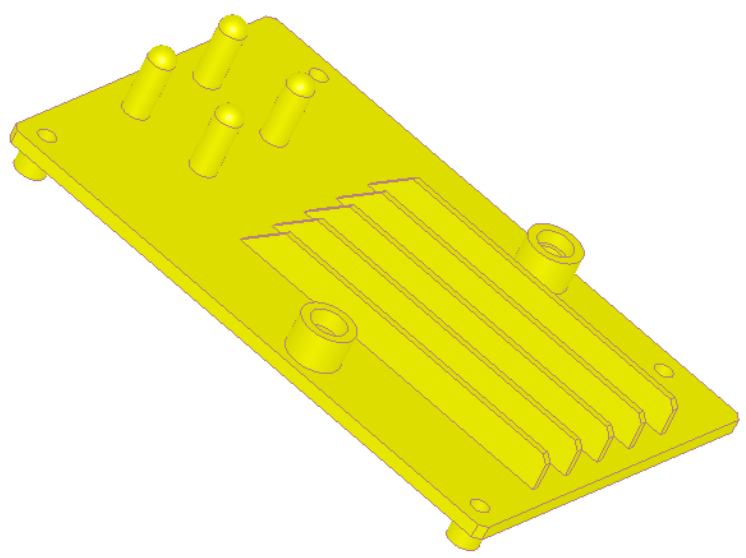

Figure 2: Heat Sink

The PMI data types included in the project models are shown in Table 4.

Table 4: PMI data types used in the models

PMI data types used in the models 
Investigating the Impact of Standards-Based Interoperability for Design to Manufacturing and Quality

\begin{tabular}{|l|l}
\hline Datums & Tolerances \\
Dimensions & All Around \\
Angular & Cylindricity \\
Diameter & Total Runout \\
Linear & Flatness \\
Radius & Perpendicularity \\
Spherical Radius & Position \\
Thickness & Profile Surface \\
Dimension Origin Symbol & Angularity
\end{tabular}

After the shape-geometry modifications were incorporated into the models, three different data sets were created to investigate how part information is exchanged with a supplier. The first data sets (8279999-905 and 827-9999-906) contain only the full-dimension-2D drawing with all of the GD\&T callouts, per ASME Y14.5, and all other necessary PMI data types. The parts can be manufactured and inspected using just the drawings. The drawings are shown in Figure 3 and Figure 4.

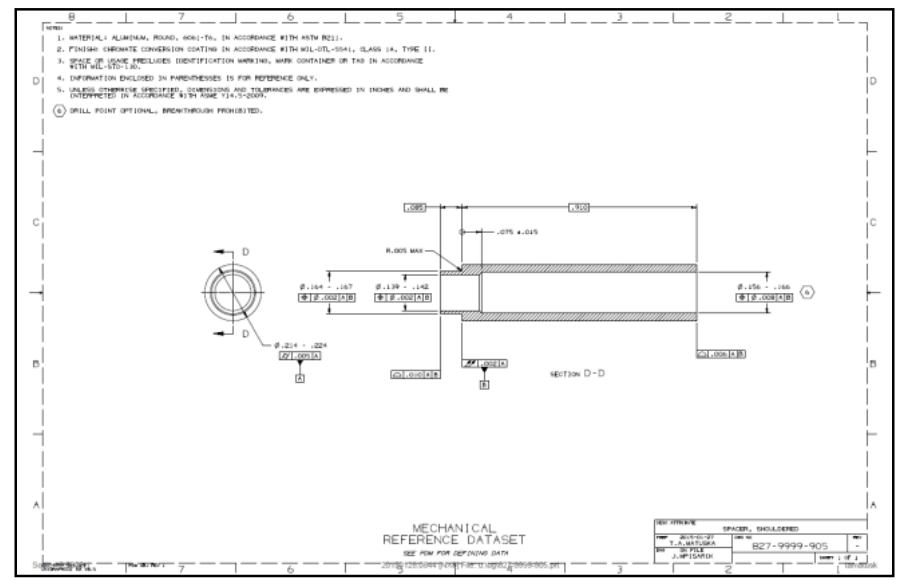

Figure 3: Rolled Standoff 827-9999-905

full-dimension-2D drawing 

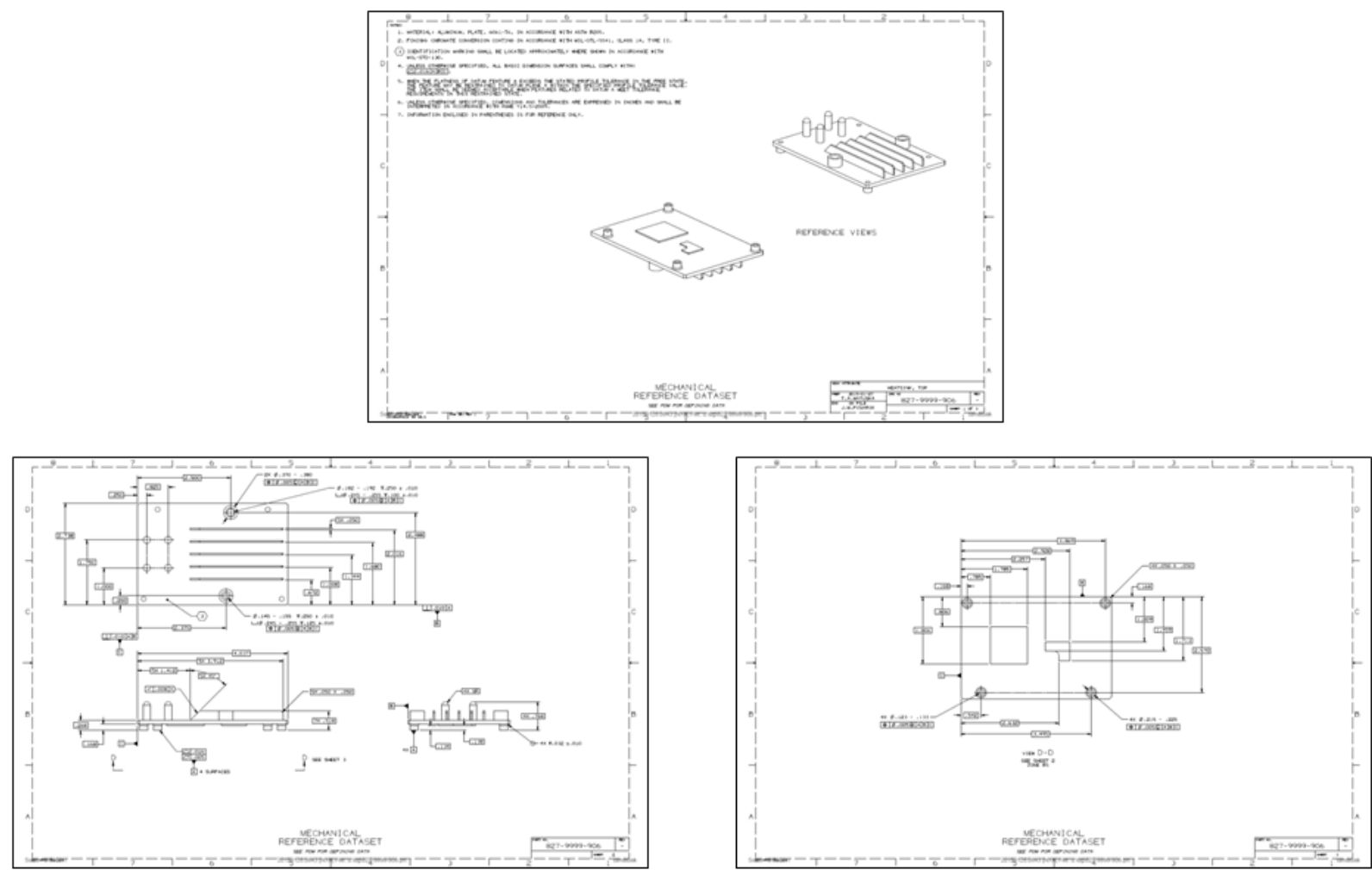

Figure 4: Heat Sink 827-9999-906 full-dimension-2D drawing

The second data sets (827-9999-907 and 827-999-908) align with ASME Y14.41 practices for creating digital-product-definition data. These data sets include a partial-dimension 2D drawing along with a 3Dshape-geometry model without embedded PMI (using the STEP AP203 format). Both the model and the drawing are necessary to manufacture and inspect the parts as shown in Figure 5 and Figure 6.
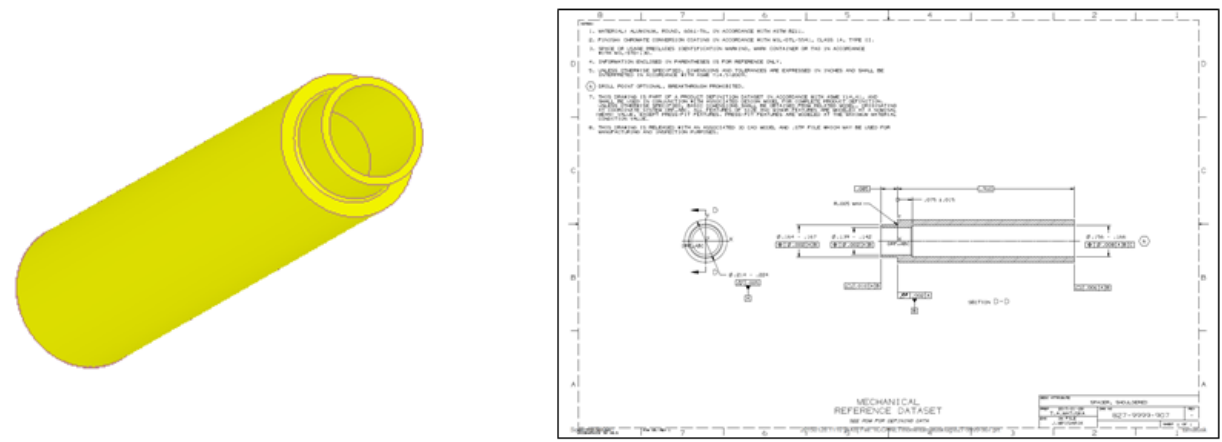

Figure 5: Rolled Standoff 827-9999-907

3D- shape-geometry model (STEP AP203) with partial-dimension-2D drawing 

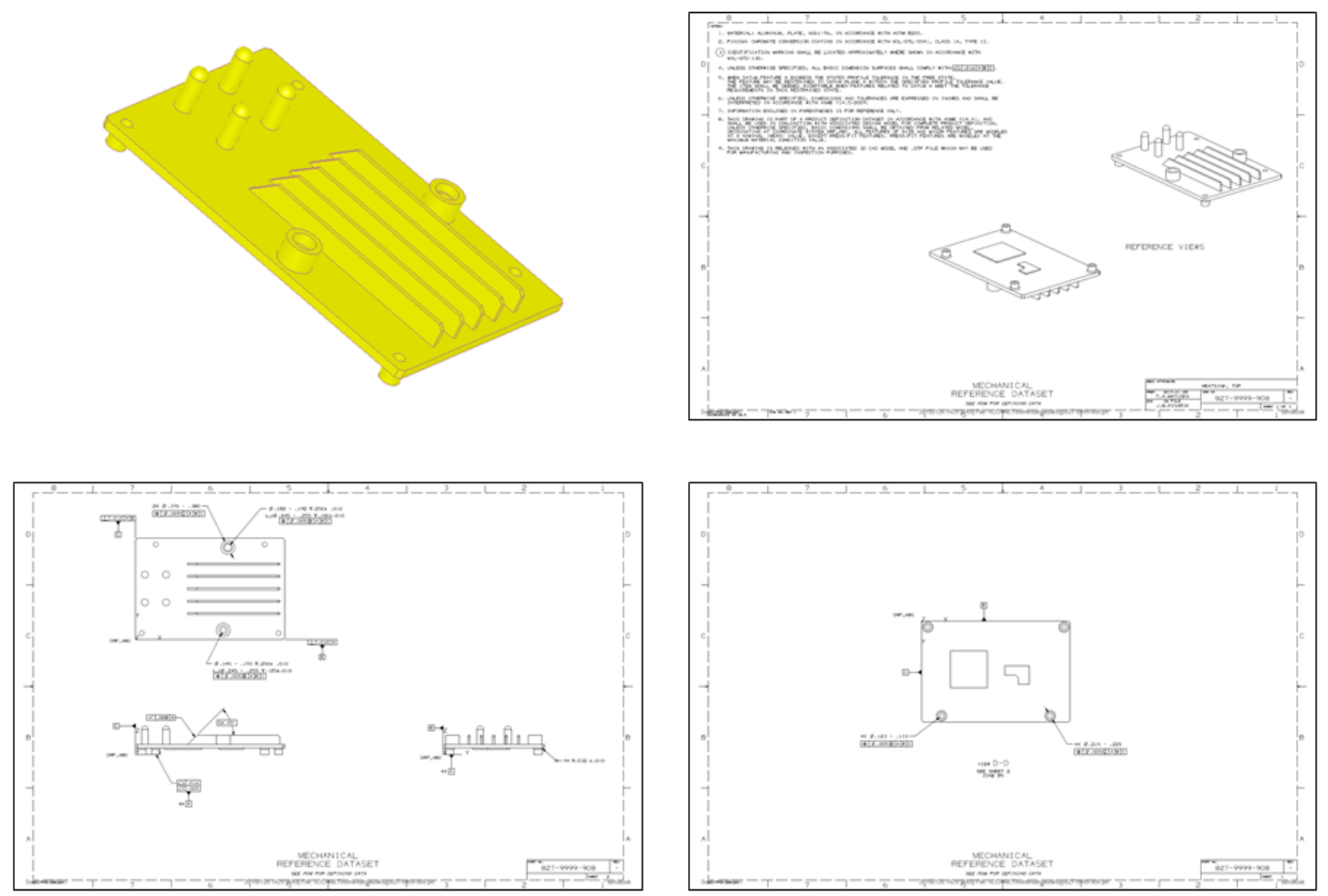

Figure 6: Heat Sink 827-9999-908

3D-shape-geometry model (STEP AP203) with partially dimensioned 2D drawing

The final data sets (827-9999-903 and 827-9999-904) contain a full-dimension-3D model with embedded PMI (using the STEP AP242 format). These parts can be manufactured and inspected completely with the 3D model, without the need of a supporting 2D drawing. These data sets are shown in Figure 7 and Figure 8. The schema aligns with the MIL-STD-31000AAppendix B data structure for PMI presentation. ${ }^{7}$ Once the native CAD model with embedded PMI was created, it was then delivered to the project team for translation into the STEP AP242 model used by the downstream CAM and CMM systems.

\footnotetext{
7 United States Department of Defense. (2013, 26 February). MIL-STD-31000A. Department of Defense Standard Practice: Technical Data Packages.
} 


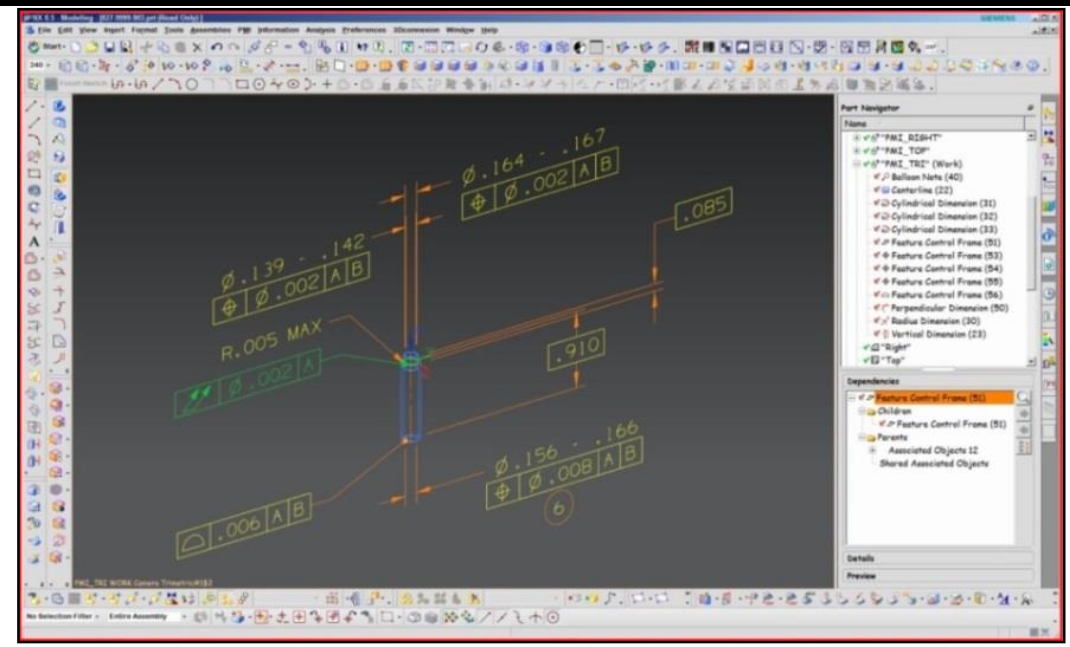

Figure 7: Rolled Standoff 827-9999-903

full-dimension-3D model (STEP AP242) with embedded PMI

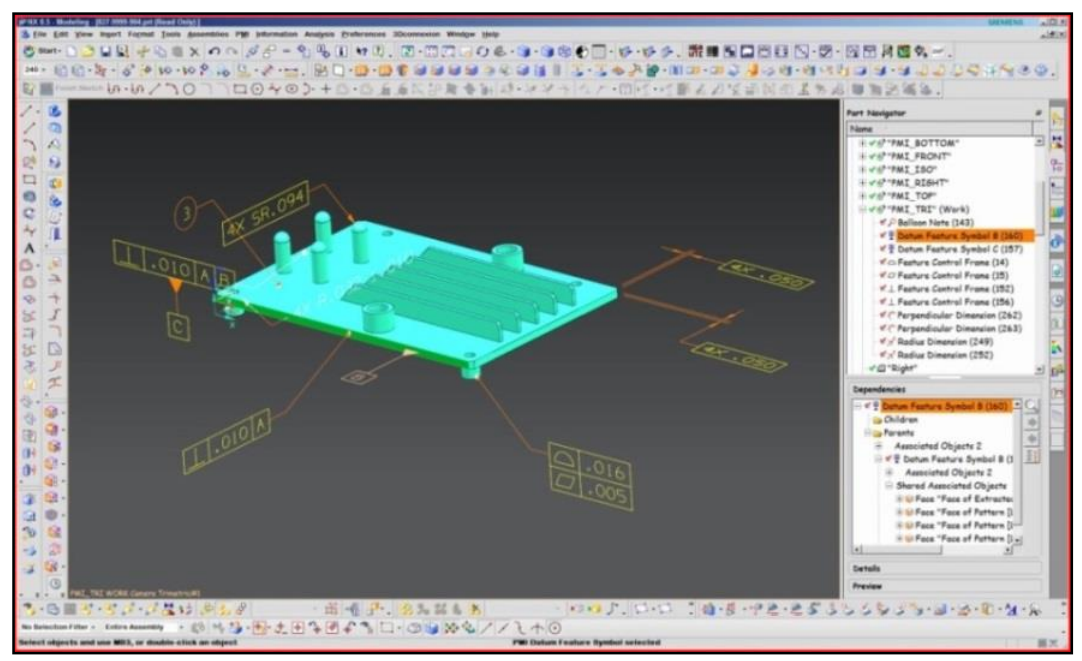

Figure 8: Heat Sink 827-9999-904

full-dimensioned-3D model (STEP AP242) with embedded PMI

\section{Map the PMI into STEP and ACIS}

According to Spatial Corporation, the 3D ACIS ${ }^{\circledR}$ Modeler geometric modeling kernel is used by many software developers, including the $C A D, C A M$, and $C M M$ industries, to provide underlying 3D modeling functionality. ${ }^{8}$ One project research task was to analyze the PMI elements in STEP AP242 and ACIS ${ }^{\circledR}$ to determine where gaps exist and what enhancements are needed to address those gaps. This analysis was performed and delivered to NIST as an early deliverable for this project. The mapping tables used as the basis for the analysis are included as Appendices B.1 and B.2. The gaps and subsequent issues are reviewed further in the results and discussion sections.

\footnotetext{
${ }^{8}$ Spatial Corp. 3D ACIS Modeling. Retrieved October 09, 2015, from Spatial Products: http://www.spatial.com/products/3d-acis-modeling.
} 
Investigating the Impact of Standards-Based Interoperability for Design to Manufacturing and Quality

Demonstrate Standards-Based Interoperability

The flow diagram shown in Figure 9 demonstrates the data-exchange process from CAD-to-CAM and CAD-to-CMM, using commercially viable solutions. Rockwell Collins performed as the OEM. Rockwell Collins designed the test parts using Siemens NX ${ }^{\mathrm{TM}}$ CAD software. Geater Machining and Manufacturing performed as the supplier. Geater used CNC Software Mastercam ${ }^{\circledR}$ for numerical control programming for the manufacture (CNC machining and turning) of the test parts. Geater used Mitutoyo MiCAT ${ }^{\mathrm{m}}$ Planner automatic measurement program generation software to enable inspection of the test parts. The data exchange process required the use of CoreTechnologie 3D_Evolution ${ }^{\odot}$ to convert data from the native NX ${ }^{\mathrm{TM}}$ CAD shape, metadata, and PMI into standards-based STEP AP242 format. ITI PDElib ${ }^{\circledR}$ data exchange library was used to complete the import from STEP AP242 into Mastercam ${ }^{\circledR}$. ITI eACIS utility library was used to complete the import from STEP AP242 into the $\mathrm{ACIS}^{\circledR}$ kernel used by MiCAT ${ }^{\mathrm{TM}}$ Planner.

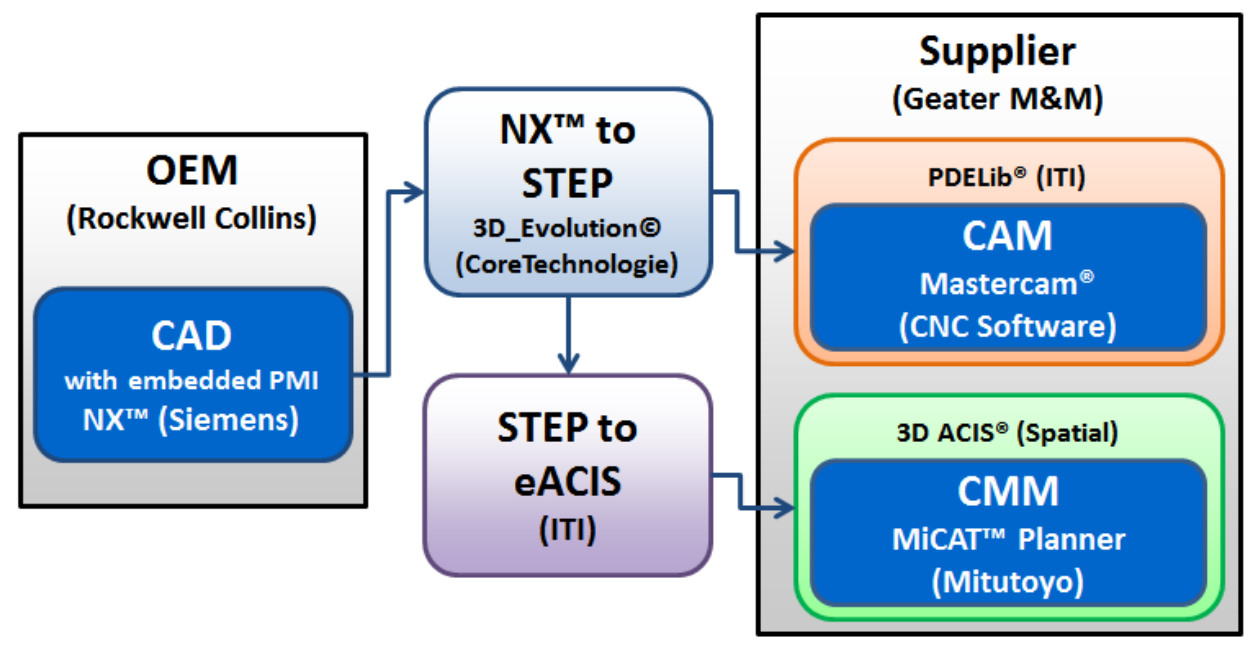

Figure 9: Data exchange process flow diagram

The software tools used for model conversion from CAD to CAM and CMM required algorithm enhancements to the currently available commercial versions to enable and fine-tune the exchange of the semantic PMI data. Issues were identified and resolved in order to successfully exchange the data. The project used an iterative approach in the issue resolution process:

- Perform data exchange for each process step,

- Evaluate the output for the required model entities at each process step,

- Identify errors encountered in the individual PMI elements,

- Modify each sub-process algorithm to address the issue, and

- Re-evaluate the updated output until each sub-process converged to a viable end-to-end data exchange solution. 
Investigating the Impact of Standards-Based Interoperability for Design to Manufacturing and Quality

CAD Process

The OEM use case process steps, referenced in Table 5, represent the activity most likely affected by the inclusion of embedded PMI in the CAD model necessary for downstream manufacturing and inspection. The OEM metrics captured for this project focus primarily on the CAD-model creation process steps, but also provide some insight into CAD-model validation and verification process. The project also provided anecdotal observations for the part-receiving-inspection use case, but those come mostly as a result of metrics captured for the CMM inspection and reporting use cases.

Table 5: CAD model creation process

\begin{tabular}{|c|l|}
\hline Process Steps & \multicolumn{1}{c|}{ OEM Steps } \\
\hline & CAD 3D model creation \\
Model Creation & Model-embedded PMI \\
& 2D PDF drawing creation \\
& CAD tool issue resolution and designer education * \\
& CAD model resolution to address CMM issues * \\
\hline
\end{tabular}

* CAD model issues and designer education demonstrate the need to overcome gaps in current state of tools and knowledge

\section{CAM Process}

The supplier CAM use case process steps represent the activity involved in CAM model creation. The project focused on the most useful metrics to record for the supplier for CAM-related process steps. The metrics demonstrate the difference between the current-state and the future-state process steps. They must provide enough detail to demonstrate the process areas most significantly affected when ingesting models with embedded PMI for CAM programming. Finally, the metrics need to align with the supplier process steps such that they could be easily recorded. It was determined that cycle-time metrics would be most useful to compare current-state to future-state for the CAM process. The supplier completed the CAM model creation process steps using the three technical data exchange scenarios and manually recorded the cycle-time for the steps.

The project reviewed the manufacturing process steps identified in the NIST Testing the Digital Thread project. ${ }^{9}$ The research compared these process steps to the manufacturing check-list steps used by the supplier. In the comparison, four general process step segments were identified. These became the segments for recording cycle-time measurement results for the project. Table 6 shows the comparison of steps for the CAM process.

Table 6: CAM model creation process

\begin{tabular}{l|l|l} 
NIST Steps & Process Steps & Supplier Steps
\end{tabular}

\footnotetext{
${ }^{9}$ Hedberg, Jr. T., Lubell, J., Fischer, L., Maggiano, L., \& Barnard Feeney, A. Testing the Digital Thread in Support of Model-Based Manufacturing and Inspection. Submitted for publication, 2015.
} 
Investigating the Impact of Standards-Based Interoperability for Design to Manufacturing and Quality

\begin{tabular}{|c|c|c|}
\hline $\begin{array}{l}\text { Gather product definition } \\
\text { Generate 3D model, if needed } \\
\text { Gather manufacturing requirements } \\
\text { Gather specification and standards requirements } \\
\text { Digest the eBOM } \\
\text { Generate mBOM } \\
\text { Determine required manufacturing processes } \\
\text { Determine required manufacturing resources } \\
\text { Interrogate product definition } \\
\text { Conduct manufacturing stacking process } \\
\text { Determine form features and process requirements } \\
\text { Determine manufacturing resource availability } \\
\text { Adjust proposed manufacturing process based on } \\
\text { resource availability }\end{array}$ & $\begin{array}{c}\text { CAM } \\
\text { Process } \\
\text { Preparation }\end{array}$ & Manufacturing process preparation \\
\hline $\begin{array}{l}\text { Generate in-process 3D model for tooling and } \\
\text { programming } \\
\text { Determine and add manufacturing notes }\end{array}$ & $\begin{array}{l}\text { CAM } \\
\text { Setup }\end{array}$ & $\begin{array}{l}\text { Draw a solid of the stock, fixture and tabstock } \\
\text { Select correct machine post } \\
\text { Set revision level in properties page } \\
\text { Set tool settings } \\
\text { Select stock model } \\
\text { Save Mastercam file as part number and } \\
\text { revision level less decimal points (xxx-xxxx- } \\
\text { xxx, REVA) }\end{array}$ \\
\hline $\begin{array}{l}\text { Create tooling models (fixtures and gauges) } \\
\text { Create tooling documentation } \\
\text { Create CAM / NC program } \\
\text { Add tooling to CAM / NC program }\end{array}$ & $\begin{array}{c}\text { CAM } \\
\text { Programming }\end{array}$ & $\begin{array}{l}\text { Check material type } \\
\text { Program part } \\
\text { Program fixtures } \\
\text { Check that coolant is on for all tools } \\
\text { Add number of shifts and distance to macro } \\
\text { programs } \\
\text { Turn on shift cancel for any tools that run the } \\
\text { full length of a strip (if applicable) }\end{array}$ \\
\hline $\begin{array}{l}\text { Create manufacturing work instructions } \\
\text { Generate additional process documentation, as needed } \\
\text { Create CAM and NC documentation } \\
\text { Process review: verify final product definition (all } \\
\text { dimensions, etc. covered by manufacturing process) } \\
\text { Process review: verify all manufacturing, process, and } \\
\text { engineering notes requirements are achieved } \\
\text { Final process sign-off }\end{array}$ & $\begin{array}{c}\text { CAM } \\
\text { Verification }\end{array}$ & $\begin{array}{l}\text { Make sure rapid retract is being used on all } \\
\text { tiles } \\
\text { Create VERICUT for fixture programs } \\
\text { Create VERICUT for part programs and } \\
\text { make sure all hardware is in place } \\
\text { Run auto-diff in VERICUT and take time to } \\
\text { ensure all excess and gouges are correct } \\
\text { Double check all drill and tap tooling against } \\
\text { print for correct sizes }\end{array}$ \\
\hline
\end{tabular}

\section{CMIM Process}

The CMM process steps were identified in a similar way as the CAM process steps. Inspection steps previously defined in the NIST Testing the Digital Thread project were compared to the steps in the supplier check-list for inspection. In the comparison, five general process step segments were identified. These became the segments for recording cycle-time measurement results for the project. Table 7 shows the comparison of steps for the CAM process.

\section{Table 7: CMM model creation process}

\begin{tabular}{|c|c|c|}
\hline NIST Steps & Project Steps & Supplier Steps \\
\hline $\begin{array}{l}\text { Gather product definition } \\
\text { Generate 3D model if needed } \\
\text { Gather inspection requirements } \\
\text { Gather specification and standards requirements }\end{array}$ & $\begin{array}{c}\text { CMM } \\
\text { Process } \\
\text { Preparation }\end{array}$ & Import model into CMM software \\
\hline
\end{tabular}


Investigating the Impact of Standards-Based Interoperability for Design to Manufacturing and Quality

\begin{tabular}{|c|c|c|}
\hline $\begin{array}{l}\text { Determine required inspection processes } \\
\text { Determine required inspection resources }\end{array}$ & & \\
\hline $\begin{array}{l}\text { Interrogate product definition } \\
\text { Balloon and identify characteristics from product } \\
\text { definition } \\
\text { Populate reporting documentation (e.g. AS9102, } \\
\text { etc.) with characteristics } \\
\text { Determine inspection resource availability } \\
\text { Adjust proposed inspection process based on } \\
\text { resource availability } \\
\text { Generate in-process 3D models, if in-process } \\
\text { inspection will occur }\end{array}$ & $\begin{array}{l}\text { CMM } \\
\text { Setup }\end{array}$ & Establish datum features \\
\hline $\begin{array}{l}\text { Create } \mathrm{CMM} \text { measurement program } \\
\text { Create } \mathrm{CMM} \text { measurement work instructions } \\
\text { Create } \mathrm{CMM} \text { measurement documentation }\end{array}$ & $\begin{array}{c}\text { CMM } \\
\text { Programming }\end{array}$ & $\begin{array}{l}\text { Measure all features on the model per print } \\
\text { specifications }\end{array}$ \\
\hline $\begin{array}{l}\text { Verify final product definition (all characteristics } \\
\text { are covered by Inspection process) } \\
\text { Verify all inspection, process, and engineering } \\
\text { notes requirements have been met } \\
\text { Final process sign-off }\end{array}$ & $\begin{array}{c}\text { CMM } \\
\text { Verification }\end{array}$ & Verify for collisions \\
\hline $\begin{array}{l}\text { Populate reporting documentation (e.g. AS9102, } \\
\text { etc.) with characteristic measurement results } \\
\text { Compare and analyze conformance of product } \\
\text { against product definition (capture deviation) }\end{array}$ & $\begin{array}{c}\text { CMM } \\
\text { Data Analysis }\end{array}$ & Run report \\
\hline
\end{tabular}

\section{Data Exchange Issue Resolution}

With the iterative data exchange approach, numerous issues were discovered and the majority resolved for the final demonstration of the CAD-to-CAM and CAD-to-CMM data exchange using models with embedded PMI. Examples of resolved issues for CAM and CMM are shown in Figure 10 and Figure 11.

Figure 10 is a snapshot of the in-development Mastercam environment with imported PMI data. Note the STEP geometric tolerance anomaly in the upper right of the image. This was corrected in a subsequent iteration.

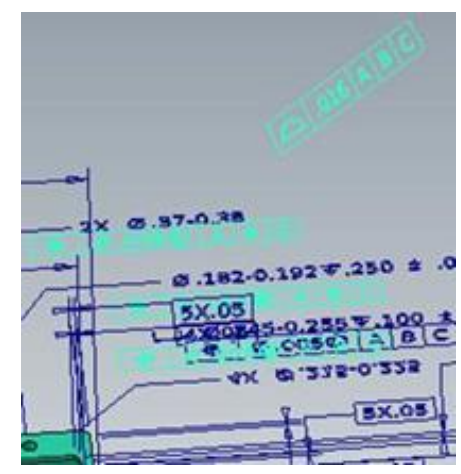

Figure 10: Snapshot of in-development Mastercam environment

Figure 11 is a snapshot of the in-development NX CAD and MiCAT CMM environments with PMI data. Note the items identified in the CAD data tree on the left. The common annotation is a complex feature that is presented in a human-readable format on the drawing. It is actually a combination of several 
Investigating the Impact of Standards-Based Interoperability for Design to Manufacturing and Quality features and characteristics presented in a non-semantic way, which is not machine-interpretable. The imported PMI with machine-interpretable representation is shown in the MiCAT view on the right.

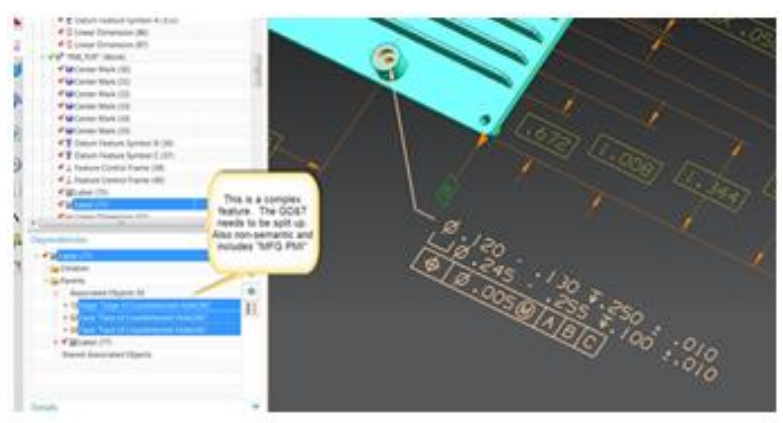

Siemens NX CAD Presentation
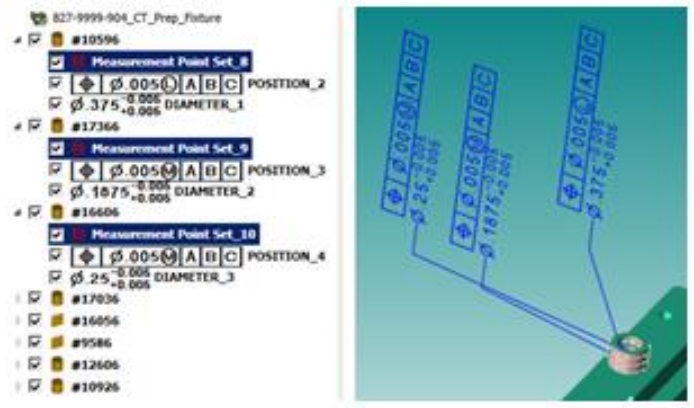

MiCAT CMM Representation

Figure 11: Snapshot of in-development NX CAD and MiCAT CMM environments

Note there were other identified issues that could not be addressed within the scope of this project.

Those issues are reviewed further in the results and discussion sections.

\section{Results}

\section{Results from Mapping PMI between STEP and ACIS}

The following PMI gaps were identified when mapping PMI between STEP AP242 and ACIS:

- Spherical dimension types (RADIUS, DIAMETER) are missing from ACIS

- Oriented and curved dimensions are missing from ACIS

- $\mathrm{ACIS}$ does not support angle selection (SMALL, LARGE, EQUAL) in an angular dimension

- Tolerance principal (ENVELOPE, INDEPENDENCY) is not supported by ACIS

- Dimension value with plus/minus bounds is not supported by ACIS

- Dimension value with qualifier (MAXIMUM, MINIMUM) is not supported by ACIS

- Very limited support for dimension modifiers (BASIC, REFERENCE, STATISTICAL) by ACIS, many are missing (CONTROLLED RADIUS, FREE STATE, ANY CROSS SECTION, etc.)

- Movable datum target is not supported by ACIS

- Geometric tolerance type (COAXIALITY) is missing from ACIS

- Limited support for tolerance zone types (DIAMETER, SPERICAL DIAMETER, PROJECTED) by ACIS, some are missing (NON-UNIFORM, RUNOUT, WITHIN A CIRCLE, etc.)

The results: STEP AP242 with embedded PMI can successfully exchange modelcentric data from design (CAD) to manufacturing (CAM) and inspection (CMM).

- Very limited support for tolerance modifiers (FREE STATE, LMC, MMC, RFS, STATISTICAL, TANGENT PLANE) by ACIS, many are missing (ANY CROSS SECTION, COMMON ZONE, etc.)

- Very limited support for datum reference modifiers (LMC, MMC) by ACIS, many are missing (FREE STATE, BASIC, TRANSLATION, etc.)

- $\mathrm{ACIS}$ does not directly support POLYLINE presentation 
Investigating the Impact of Standards-Based Interoperability for Design to Manufacturing and Quality

\section{Results from Embedded PMI Data Exchange}

Development and demonstration of a process to exchange standards-based models with embedded PMI from design to downstream systems was successful within the scope of the limited test models used in this project. The validation results, as defined by PMI element counts, for the downstream models are provided in Table 8. The validation shows that all dimensions, tolerances, and datum features were properly transformed and exchanged.

Table 8: Validation of model transformations using embedded PMI entity count

\begin{tabular}{|l|c|c|c|c|c|c|c|c|c|c|}
\hline $\begin{array}{l}\text { PMI Elements } \\
\text { (by format) }\end{array}$ & \multicolumn{2}{|c|}{ NX } & \multicolumn{2}{c|}{ STEP } & \multicolumn{2}{c|}{ ACIS } & \multicolumn{2}{c|}{ Mastercam } & \multicolumn{3}{c|}{ MiCAT } \\
\hline Model (827-9999) & $-\mathbf{9 0 3}$ & $\mathbf{- 9 0 4}$ & $\mathbf{- 9 0 3}$ & $\mathbf{- 9 0 4}$ & $\mathbf{- 9 0 3}$ & $\mathbf{- 9 0 4}$ & $\mathbf{- 9 0 3}$ & $\mathbf{- 9 0 4}$ & $\mathbf{- 9 0 3}$ & $\mathbf{- 9 0 4}$ \\
\hline Dimension & 8 & 54 & 8 & 54 & 8 & 54 & 8 & 54 & 8 & 54 \\
\hline Tolerance & 6 & 13 & 6 & 13 & 6 & 13 & 6 & 13 & 6 & 13 \\
\hline Datum Feature & 2 & 3 & 2 & 3 & 2 & 3 & 2 & 3 & 2 & 3 \\
\hline $\begin{array}{l}\text { Notes } \\
\text { not semantic data) }\end{array}$ & 7 & 8 & 7 & 8 & 0 & 0 & 7 & 8 & 0 & 0 \\
\hline Total & 23 & 78 & 23 & 78 & 16 & 70 & 23 & 78 & 13 & 68 \\
\hline
\end{tabular}

Automated validation of the downstream models using analysis software during algorithm development was performed using techniques described in a separate NIST project. ${ }^{10}$ As indicated in Table 8 , general notes could not be mapped to ACIS and were not transferable to the MiCAT Planner. Other development roadblocks are discussed later.

\section{Results from CAD Model Creation}

Results for CAD model creation are shown in Table 9. For each part, three data sets were generated. The future-state data set (-903 and -904) included the 3D model (STEP AP242) with embedded PMI. The current-state had two significant data sets to compare against the future-state. The first current-state data set (-905 and -906) provided a full-annotated-2D drawing with dimensions and PMI. The part is represented fully and can be manufactured from the drawing. The second current-state data set (-907 and -908) contains the 3D-shape-geometry model (STEP AP203) and a 2D drawing with the PMI. This data set requires both the model and the drawing together to manufacture the part.

Table 9: CAD model creation metrics

\begin{tabular}{|c|c|c|c|c|c|c|}
\hline \multirow{2}{*}{$\begin{array}{l}\text { CAD Metrics } \\
827-9999\end{array}$} & \multicolumn{3}{|c|}{ Rolled Standoff } & \multicolumn{3}{|c|}{ Heat Sink } \\
\hline & -903 & -905 & -907 & -904 & -906 & -908 \\
\hline
\end{tabular}

\footnotetext{
${ }^{10}$ NIST Collaborative Agreement: 70NANB14H256. (2015). Validation for Downstream Computer Aided Manufacturing and Coordinate Metrology Processes.
} 
Investigating the Impact of Standards-Based Interoperability for Design to Manufacturing and Quality

\begin{tabular}{|c|c|c|c|c|c|c|}
\hline 2D PDF drawing & --- & $\begin{array}{l}\text { full dimension } \\
\text { with 2D PMI } \\
\text { annotation }\end{array}$ & $\begin{array}{l}\text { key 2D PMI } \\
\text { annotation } \\
\text { only (PDD) }\end{array}$ & --- & $\begin{array}{l}\text { full dimension } \\
\text { with 2D PMI } \\
\text { annotation }\end{array}$ & $\begin{array}{l}\text { key 2D PMI } \\
\text { annotation } \\
\text { only (PDD) }\end{array}$ \\
\hline 3D model & $\begin{array}{l}\text { includes } \\
\text { embedded } \\
\text { PMI }\end{array}$ & not provided & $\begin{array}{l}\text { with no } \\
\text { embedded } \\
\text { PMI }\end{array}$ & $\begin{array}{l}\text { includes } \\
\text { embedded } \\
\text { PMI }\end{array}$ & not provided & $\begin{array}{c}\text { with no } \\
\text { embedded } \\
\text { PMI }\end{array}$ \\
\hline Number of PMI entities & $23\left(24^{*}\right)$ & --- & --- & $78\left(90^{*}\right)$ & --- & --- \\
\hline $\begin{array}{l}\text { CAD model creation } \\
\text { (modified existing part) }\end{array}$ & 0.5 hours & 0.5 hours & 0.5 hours & 0.5 hours & 0.5 hours & 0.5 hours \\
\hline Model-embedded PMI & 3.0 hours & --- & --- & 6.0 hours & --- & --- \\
\hline 2D PDF drawing creation & 0.5 hours & 1.0 hours & 0.7 hours & 0.5 hours & 2.4 hours & 1.3 hours \\
\hline $\begin{array}{l}\text { CAD tool issue resolution } \\
\text { and designer education }\end{array}$ & 9.0 hours & 0.5 hours & 0.1 hours & 4.9 hours & 0.5 hours & 0.1 hours \\
\hline $\begin{array}{l}\text { CAD model resolution } \\
\text { to address downstream } \\
\text { issues }\end{array}$ & $\begin{array}{r}2.3 \text { hours } \\
+4.5 \text { hours } \\
\text { to learn NX }\end{array}$ & --- & --- & $\begin{array}{r}3.0 \text { hours } \\
+1.3 \text { hours } \\
\text { to learn NX}\end{array}$ & $\begin{array}{l}\text { original dwg } \\
\text { missing dim - } \\
\text { required ECO }\end{array}$ & --- \\
\hline
\end{tabular}

* Original PMI entity count based on objects found in the NX Part navigator - eventually reduced count by issue resolution

\section{Results from CAM Model Creation}

The supplier steps defined earlier were the basis for the four general project steps that condensed into recordable metrics in Table 10. These metrics show the difference between the current-state processes and the future-state process. Recall that two current-state processes were demonstrated. The first data set (-905 and -906) contained a full-dimension-2D drawing including all PMI. The second data set (-907 and -908) contained a 3D-shape-geometry model (STEP AP203) and a 2D drawing with the key PMI annotations. The future-state data set (-903 and -904) contained a full-defined-3D model with embedded PMI (STEP AP242).

Regardless of the data exchange scenario, the CAM process preparation steps were the same for each and the cycle-time did not show any difference. Likewise, due to the simplicity of the rolled standoff, no significant cycle-time difference was recorded for the CAM programming and verification steps.

Table 10: CAM model creation metrics

\begin{tabular}{|c|c|c|c|c|c|c|}
\hline \multirow{2}{*}{$\begin{array}{l}\text { CAM Metrics } \\
827-9999\end{array}$} & \multicolumn{3}{|c|}{ Rolled Standoff } & \multicolumn{3}{|c|}{ Heat Sink } \\
\hline & $\begin{array}{l}-903 \\
\text { 3D model with } \\
\text { embedded PMI }\end{array}$ & $\begin{array}{c}-905 \\
\text { 2D drawing } \\
\text { fully annotated }\end{array}$ & $\begin{array}{c}-907 \\
\text { 2D PMI drawing } \\
\text { and 3D model }\end{array}$ & $\begin{array}{l}-904 \\
\text { 3D model with } \\
\text { embedded PMI }\end{array}$ & $\begin{array}{c}-906 \\
\text { 2D drawing } \\
\text { fully annotated }\end{array}$ & $\begin{array}{c}-908 \\
\text { 2D PMI drawing } \\
\text { and 3D model }\end{array}$ \\
\hline $\begin{array}{l}\text { CAM Process Preparation } \\
\text { a) Gather information } \\
\text { b) Analyze job } \\
\text { c) Determine approach }\end{array}$ & $\begin{array}{l}3.25 \text { hours } \\
\text { a) } 0.25 \text { hours } \\
\text { b) } 0.50 \text { hours } \\
\text { c) } 2.50 \text { hours }\end{array}$ & $\begin{array}{l}3.25 \text { hours } \\
\text { a) } 0.25 \text { hours } \\
\text { b) } 0.50 \text { hours } \\
\text { c) } 2.50 \text { hours }\end{array}$ & $\begin{array}{l}3.25 \text { hours } \\
\text { a) } 0.25 \text { hours } \\
\text { b) } 0.50 \text { hours } \\
\text { c) } 2.50 \text { hours }\end{array}$ & $\begin{array}{l}3.83 \text { hours } \\
\text { a) } 0.33 \text { hours } \\
\text { b) } 0.50 \text { hours } \\
\text { c) } 3.00 \text { hours }\end{array}$ & $\begin{array}{l}3.83 \text { hours } \\
\text { a) } 0.33 \text { hours } \\
\text { b) } 0.50 \text { hours } \\
\text { c) } 3.00 \text { hours }\end{array}$ & $\begin{array}{l}3.83 \text { hours } \\
\text { a) } 0.33 \text { hours } \\
\text { b) } 0.50 \text { hours } \\
\text { c) } 3.00 \text { hours }\end{array}$ \\
\hline
\end{tabular}


Investigating the Impact of Standards-Based Interoperability for Design to Manufacturing and Quality

\begin{tabular}{|c|c|c|c|c|c|c|}
\hline $\begin{array}{l}\text { CAM Setup } \\
\text { a) Model preparation } \\
\text { b) Pre-program setup }\end{array}$ & $\begin{array}{l}0.45 \text { hours } \\
\text { a) } 0.00 \text { hours } \\
\text { b) } 0.45 \text { hours }\end{array}$ & $\begin{array}{l}0.52 \text { hours } \\
\text { a) } 0.07 \text { hours } \\
\text { b) } 0.45 \text { hours }\end{array}$ & $\begin{array}{l}0.45 \text { hours } \\
\text { a) } 0.00 \text { hours } \\
\text { b) } 0.45 \text { hours }\end{array}$ & $\begin{array}{l}\mathbf{0 . 6 8} \text { hours } \\
\text { a) } 0.45 \text { hours } \\
\text { b) } 0.23 \text { hours }\end{array}$ & $\begin{array}{l}0.64 \text { hours } \\
\text { a) } 0.52 \text { hours } \\
\text { b) } 0.12 \text { hours }\end{array}$ & $\begin{array}{l}0.40 \text { Hours } \\
\text { a) } 0.28 \text { hours } \\
\text { b) } 0.12 \text { hours }\end{array}$ \\
\hline $\begin{array}{l}\text { CAM Programming } \\
\text { a) Part programming } \\
\text { b) Tooling preparation }\end{array}$ & $\begin{array}{l}1.00 \text { hours } \\
\text { a) } 0.50 \text { hours } \\
\text { b) } 0.50 \text { hours }\end{array}$ & $\begin{array}{l}1.00 \text { hours } \\
\text { a) } 0.50 \text { hours } \\
\text { b) } 0.50 \text { hours }\end{array}$ & $\begin{array}{l}1.00 \text { hour } \\
\text { a) } 0.50 \text { hours } \\
\text { b) } 0.50 \text { hours }\end{array}$ & $\begin{array}{l}3.23 \text { hours } \\
\text { a) } 3.01 \text { hours } \\
\text { b) } 0.22 \text { hours }\end{array}$ & $\begin{array}{l}3.13 \text { hours } \\
\text { a) } 2.75 \text { hours } \\
\text { b) } 0.38 \text { hours }\end{array}$ & $\begin{array}{l}2.30 \text { hours } \\
\text { a) } 2.08 \text { hours } \\
\text { b) } 0.22 \text { hours }\end{array}$ \\
\hline Total & 4.85 hours & 4.92 hours & 4.85 hours & 8.16 hours & 8.10 hours & 7.06 hours \\
\hline
\end{tabular}

\section{Results from CMM Model Creation and Inspection}

Once again, the cycle-time metrics show the difference between the current-state processes and the future-state process. Recall that the first data set (-905 and -906) started with only a full-dimension-2D drawing including all PMI. But in this case, the supplier was able to take advantage of the model that was already created for the CAM process and re-use it in the CMM process. The same occurred for the second data set (-907 and -908), which contained a 3D-shape-geometry model (STEP AP203) and a 2D drawing with the key PMI annotation. The future-state data set (-903 and -904) contained a fulldefinition-3D model with embedded PMI (STEP AP242). The metrics for CMM model creation are shown in Table 11.

\section{Table 11: CMM model creation and part inspection process}

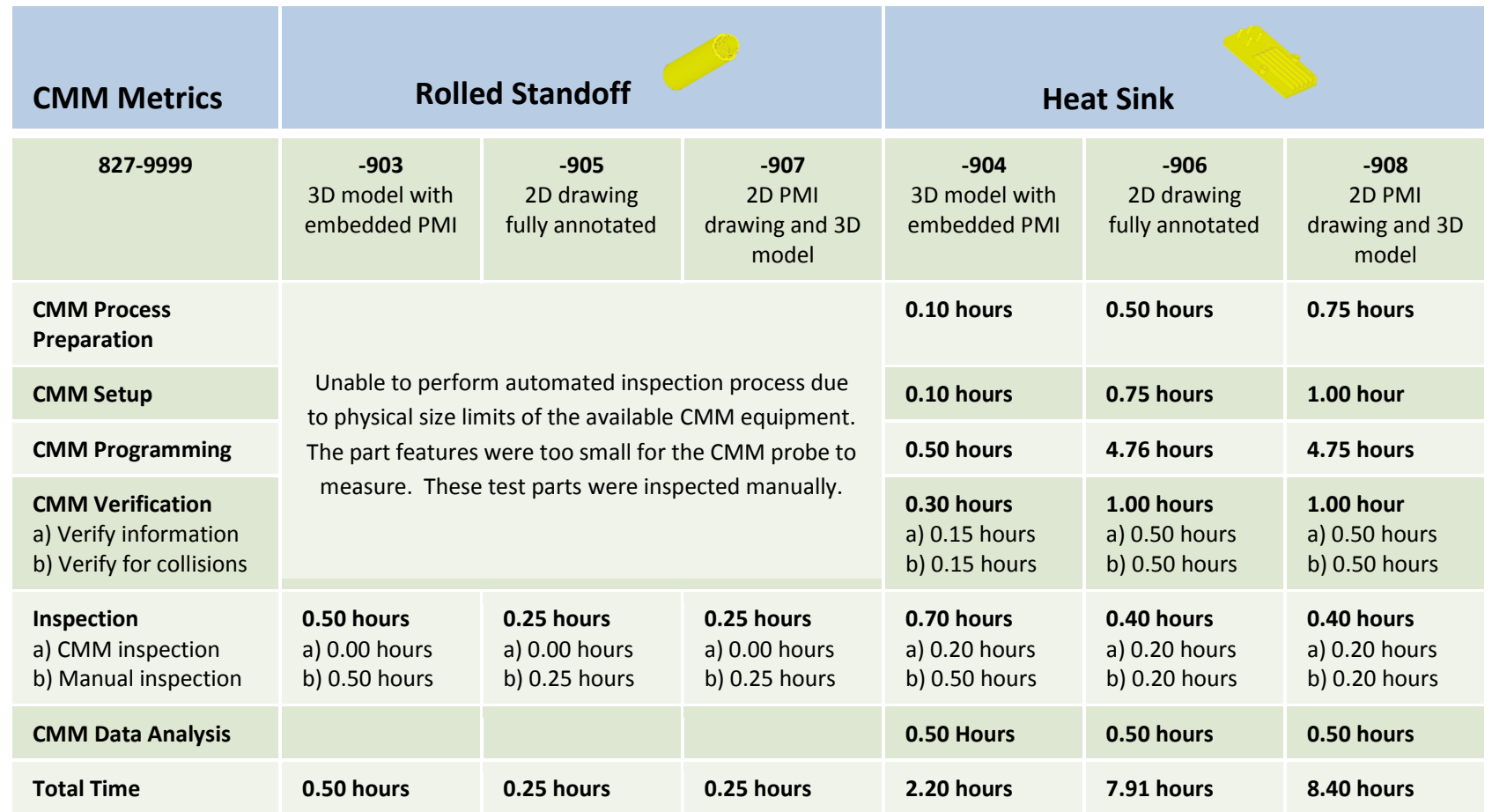


Investigating the Impact of Standards-Based Interoperability for Design to Manufacturing and Quality

Discussion and Recommendations

\section{Model Validation and Verification}

Standards-based workflow for design to manufacturing and inspection involves exchange of CAD-toAP242-to-CAM-and-CMM models. Validation and verification of this translation process is important, especially for regulated industries. An important part of quality assurance is traceability back to the design definition. To assure compliance at any point in the manufacturing or inspection process, it is essential to have validation and verification of the models throughout the data exchange process. A draft of ASME Y14.41.1 3D Model Data Organization Schema ${ }^{11}$ is currently defining Critical Metadata Elements based upon MIL-STD 31000A Department of Defense Standard Practice: Technical Data Packages, Appendix B MBD Model Organizational Schema. ${ }^{12}$ Once complete, these metadata elements will need to be supported by the STEP AP242 Model-Based Definition. Similar to ensuring coverage of GD\&T elements defined by AMSE Y.14.5, the 3D metadata elements being defined by ASME Y14.41.1 are necessary in the AP242 model to fully support data interoperability for 3D models with embedded PMI.

\section{ACIS and Embedded PMI Gaps}

The PMI-element count was used as a metric to determine that the model was imported correctly as it moved from the native-CAD model through STEP AP242, ACIS, and ultimately into the CAM and CMM models. Several iterations and changes to the CAD-model-embedded PMI were required to achieve acceptable transformation into the downstream formats for CAM and CMM. Several iterations of the application algorithms were also required to enable the transformation.

Verification and validation tools are available to identify model-based data quality issues that impact downstream reuse for tooling, simulation, and data exchange. Repair tools also offer diagnostics, translation, healing, and repair of CAD geometry for downstream model use. Types of model quality issues include:

- $\quad$ Geometry that impedes model translation or downstream reuse of CAD models

- Unrealistic features that require changes during CAM modeling

- $\quad$ Unrealistic or ambiguous PMI features that require changes during CMM modeling

- Undocumented changes caused by revisions or engineering changes

- Unintended changes caused by complex parametric relationships unknown to CAD users

Additional work is needed to overcome some deficiencies in ACIS to enable embedded-PMI-data exchange. One potential solution might involve using ACIS attributes as a mechanism to provide the missing or incomplete information. However, since this method would not be a semantic

\footnotetext{
${ }^{11}$ American Society of Mechanical Engineers. Y14.41.1. 3D Model Data Organization Schema (in development). ASME.

12 United States Department of Defense. (2013, 26 February). MIL-STD-31000A. Department of Defense Standard Practice: Technical Data Packages.
} 
Investigating the Impact of Standards-Based Interoperability for Design to Manufacturing and Quality

representation, an agreed upon specification between the sender and the receiver would be required to interpret the augmented data correctly.

Likewise, with the polyline presentation in STEP, ACIS wire bodies could be created and associated to the PMI data using attributes. But again, the sender and receiver would need to agree upon a common specification to successfully exchange the data and its semantic meaning. ACIS does support presentation information in a more semantic form, but this is not the preferred (or implemented) method in STEP.

\section{CAD Process Observations}

One unexpected but not un-common issue occurred. The original heat sink data set with the full dimension 2D drawing (-906), and without a 3D model, was provided to the supplier with two missing dimensions. The supplier discovered the missing dimensions while the model for the CAM and CMM processes was being created. The supplier had to request an updated drawing from the OEM for the missing dimensional information. This required an ECO, which had significant impact on cycle time and delivery schedule for the part. Figure 12 shows the missing dimensions. Only when you rely on 2D drawings for information does a missing dimension become relevant. Missing dimensions are not possible when using 3D model with embedded PMI.

There are anticipated benefits in the part validation, procurement, and receiving inspection, as well as for the ECO process. These areas would be good candidates for a future, more definitive ROI study of the digital thread. 

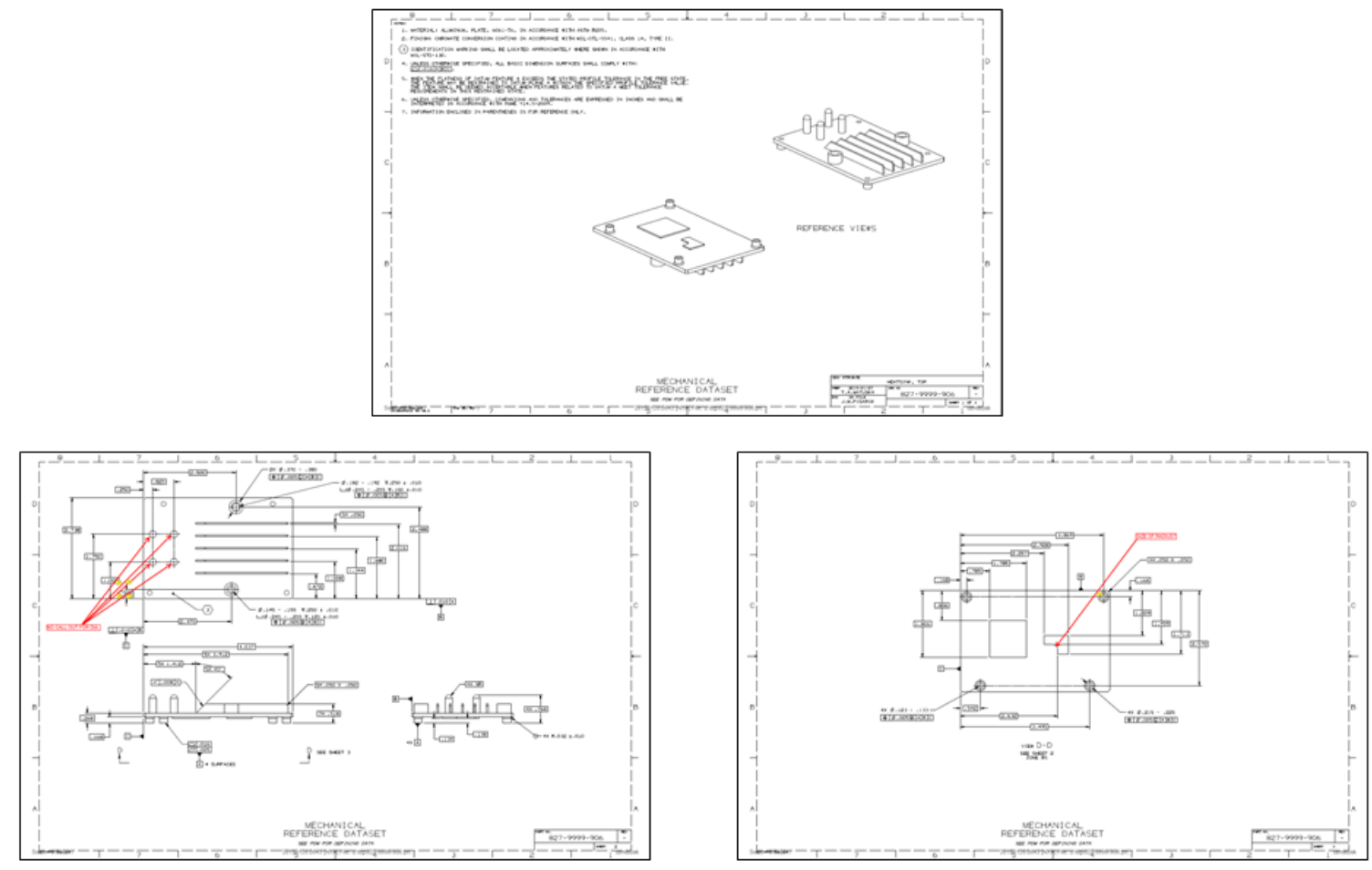

Figure 12: CAD model creation - missing dimensions

Several observations were made about the creation of the 3D CAD model with embedded PMI. During the time of CAD-model creation, some learning curve was required for the designer to become familiar with methods to both present and represent PMI annotations. User training on embedded PMI with the CAD system is absolutely necessary. There are challenges to create embedded PMI that is both human interpretable and machine readable. The inherited 3D-annotation views do not necessarily transfer to a 2D-visualization format. The 2D-GD\&T presentation within the CAD software is not always easily transferred to the 3D-model representation. Critical for the support of downstream model usage is the understanding and use of a model schema that organizes data elements and standardizes how the data elements relate to one another. Edge versus face or surface selection for PMI annotation is especially important for machine-readable-downstream use. Even though human interpretation appears straight forward; there can easily be redundant association with the model that creates issues with the downstream manufacturing and inspection systems.

It was observed that for the data sets containing a 2D drawing, the drawing includes a non-semantic presentation note stating, "Unless otherwise specified, all basic dimensions (as found in the 3D model) shall comply with: $\triangle$. $016|\mathrm{~A}| \mathrm{B} \mid \mathrm{C}$." Only the key GD\&T (PMI) items are annotated in the 2D drawing, all unspecified GD\&T is implied in the note. Currently, there is no recommended practice to incorporate this UOS functionality in 3D models with embedded-PMI representation. Industry recognizes value in the cycle-time efficiency from the use of blanket tolerances. Many features share the same tolerance and if each required explicit tolerance definition it would be too time-consuming. If a blanket tolerance 
Investigating the Impact of Standards-Based Interoperability for Design to Manufacturing and Quality is not possible with embedded-PMI representation, then the time required for CAD model creation will be prohibitive for industry to move toward acceptance of full-dimension-model-based definition.

\section{CAM Process Observations}

Observations from the supplier indicate that shape-geometry imported using the STEP AP242 format was as readily imported as it was from the STEP AP203 format. The AP242 model also provided access to the semantic representation of PMI data. The ITI library used by Mastercam to support import of STEP AP242 models provides an API to set up PMI-to-geometry associations, display the associations, and allow the associations to be saved within the Mastercam file.

The supplier was able to generate toolpath data using the imported STEP files but with a slight loss of efficiency. This efficiency loss was due to the time the operator took to manually validate the CAM model to the CAD model with embedded PMI. As the confidence level in the model-based process grows, it is expected that this inefficiency with the operator will be eliminated. Model-based validation tools could help reduce the cycle-time, while ensuring data exchange continuity and model quality. There would be reduced risk of error between CAD and CAM models and there would be more opportunity to automate validation of the CAD model to the CAM model.

There were issues with the method Mastercam chose to display the PMI. For human-readable visualization the CAM model presentation looked like a "fur-ball" of information with no organization, as shown in Figure 13.

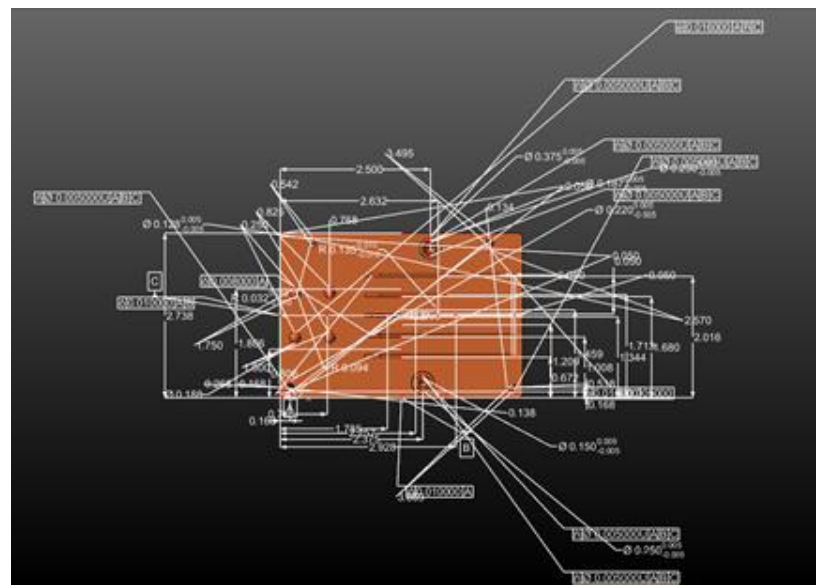

Figure 13: Dimensions imported as a "fur-ball" in CAM presentation

The imported annotations rebuilt in Mastercam using the semantic-representation data did not exactly match the original presentation data. This resulted in missing or difficult to interpret visual information. Figure 14 is an example of presentation in the original view which did not meaningfully present in another 3D view. 


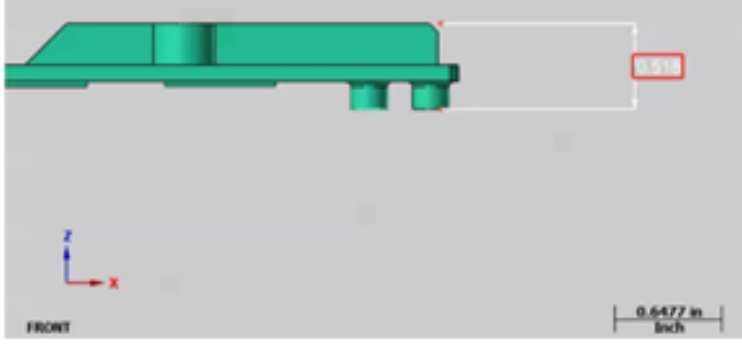

Presentation is useful in original view

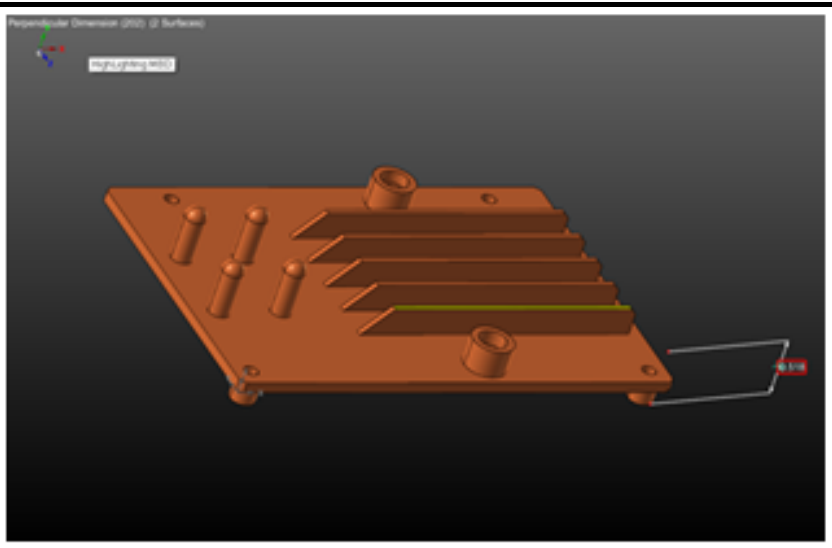

Presentation is not useful in this 3D view

Figure 14: Difficult to interpret visual presentation

As shown in the results, there was no significant improvement in cycle time from the current-state to the future-state CAM model creation using embedded PMI. It actually took more cycle time to process models with the embedded PMI than it did with the 3D-shape-geometry model because the supplier spent additional time to validate the embedded information. No quality advantage was seen in the CAM model creation and part manufacture as a result of embedded PMI. It may be that no significant improvement in cycle time or quality was measured due to the simplicity of the test models. The team expects that there would be improvement in CAM model creation when applied to more complex models.

\section{CMM Process Observations}

Similar observations of the results for CMM-model creation indicate that shape-geometry is imported the same as the STEP AP203 model when using the STEP AP242 to eACIS converter. Furthermore, STEP AP242 model import using this intermediate exchange provides access to the semantic PMI data originally in the STEP file. This provides significant automation of data entry into the CMM system. The PMI data was usable for CMM programming by the MiCAT Planner application.

CMM-model creation demonstrated the most significant improvements from importing an embedded PMI model. Importing the model with embedded PMI required just 1.70 hours for CMM process preparation, set-up, programming, verification and inspection. When using the full-dimension-2D drawing the same activity required 7.40 hours and when using the 3D-shape-geometry model with a partial-dimension-2D drawing required 7.90 hours. In all, exchanging a 3Dmodel with embedded PMI demonstrates more than 4-times improvement in cycle-time over drawing-based or shape-geometrymodel-based practices.

Upon delivery of the physical parts for inspection, an unexpected issue was encountered. The supplier was unable to inspect some features on the heat sink, and none of the features of the rolled standoff using the CMM process as originally planned. This issue was due to the physical-size limits of the available CMM equipment. As shown in Figure 15, the part features were too small for the CMM probe 
Investigating the Impact of Standards-Based Interoperability for Design to Manufacturing and Quality

to measure even with successful model import. The manual inspection cycle-time was recorded to

The conclusion: Model-centric CAD-to-CAM and CAD-to-CMM data exchange using STEP AP242 is a viable part of the MBE vision, but there are still gaps to address.

cover the areas not able to be measured using the CMM system. The manual-inspection metric demonstrates that even with full-model-based definition, a human-in-the-loop will sometimes still have significant process impact.

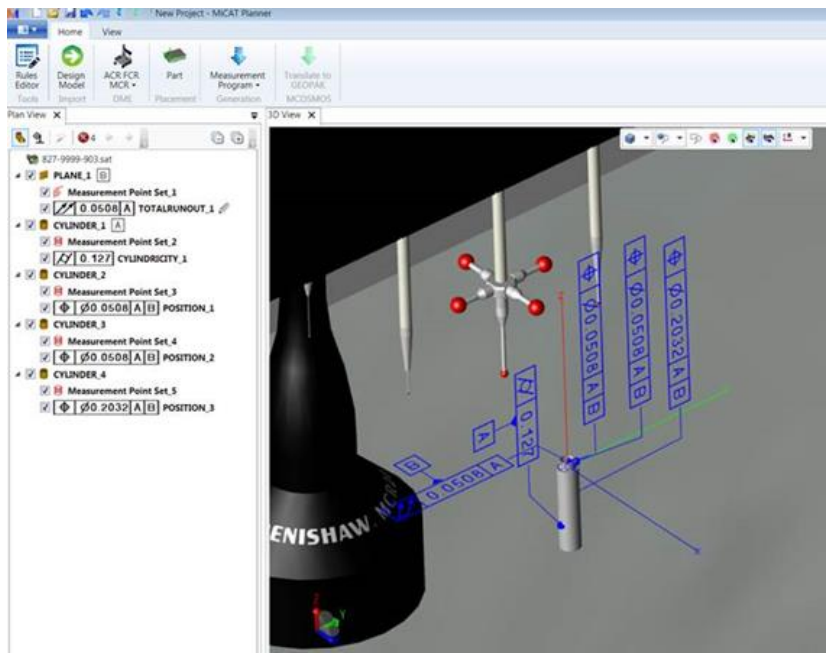

Figure 15: Physical measurement limitation even with successful model import

\section{Conclusions}

\section{Tools}

It was demonstrated that there is benefit from the CMM-system ability to interpret embedded-PMI information versus using nominal shape-geometry-model dimensions. It is anticipated that the same benefit could be gained by CAM software as well. While the basic ability to receive the embedded PMI was achieved, the CAM tools require further development to fully leverage the benefit of receiving that data.

In a number of instances, embedded PMI created by the designer does not align well to the needs of downstream-machine consumption. Since PMI-authoring capabilities of CAD systems have evolved from origins where 2D visualization of PMI was the requirement, current CAD systems allow designers to create PMI content that is, at best, partially useable for downstream consumption. Embedded-PMI rules should be implemented in CAD systems to better align model creation with the downstreammachine-interpretable expectations. 
Investigating the Impact of Standards-Based Interoperability for Design to Manufacturing and Quality

CAD-model structures are not optimized for downstream consumption. The ability to capture groupings of design features that represent geometric sets that correspond to equivalent manufacturing features is needed for downstream use and no method exists currently to achieve this functionality.

\section{Standards}

The project team recommends certain gaps be addressed by the STEP community (standards development and implementer forum). During the course of the project, it was observed that there is incomplete PMI coverage and recommended practices for the standards. Two examples illustrate the need for more coverage. There is the industry practice to use an unless-otherwise-specified tolerance callout as a general note. Although a workaround was achieved, a recommended practice is needed for this often-used callout to properly account for the required geometry associations. The second example is that surface-texture or surface-finish PMI are not yet implemented by the STEP community. A development activity to support this construct is necessary. This also necessitates a recommended practice document and the introduction of a test case into future test rounds of the STEP CAX Implementer Forum. ${ }^{13}$

\section{Processes}

The project demonstrated the cycle-time benefits of the future-state process. This is based upon a small-sample-size demonstration, but the authors believe the results are potentially scalable for increased model complexity and PMI-element counts. Significant reduction in cycle time for CMM model creation and characteristic analysis was observed. Cycle-time reduction was not conclusive for CAM-model creation however, and additional research is required to better understand the implications. It is recommended that additional testing of the process be completed over a broader sample size. Future research could seek out opportunities to increase the participants in the testing activity. This would result in a broader range of example data to work from and provide an opportunity to better assess the impact of variation in both design and processes.

It was clear that designer education is not aligned with requirements for downstream-PMI consumption, especially for machine-interpretable expectations. Industry needs recommended practices for proper association of PMI to geometry elements. There would also be value in a post-process to repair PMI geometry associations so they are complete and consistent. CAD systems should be augmented to provide design rules for creation of embedded PMI with downstream machine consumption in mind or, at a minimum, recommended practice documents need to be developed to guide designers as they annotate 3D models with PMI data. Verification tools are needed to ensure that recommended practices have been followed prior to the release of models for downstream consumption.

There are anticipated benefits in the part validation, procurement, and receiving inspection, as well as for the ECO process. These areas would be good candidates for a future, more definitive ROI study of the digital thread.

\footnotetext{
${ }^{13}$ PDES, Inc. and ProSTEP iViP. CAx Implementor Forum. Retrieved October, 09, 2015, from https://cax-if.org/index.html.
} 
Investigating the Impact of Standards-Based Interoperability for Design to Manufacturing and Quality

The latest version of $\mathrm{AS} 9102^{14}$, the aerospace standard for reporting FAl results, suggests the potential exists to improve FAI reporting, particularly through automation. There is also potential for developing a visual presentation that ties metrology results and MBD. Lastly, there is potential mechanism to provide metrology results feedback to upstream users for analysis and prediction to better consider design decisions and manufacturing technologies for future products.

\section{Summary}

In summary, motivation exists for industry to continue its drive for the MBE vision through modelcentric data interoperability for design to manufacturing and quality inspection. A number of conclusions have been drawn from the research performed under this project. An attempt has been made to organize them broadly into categories of tools, standards, and processes. Fundamentally, the project successfully demonstrated the value of standards-based CAD-to-CAM and CAD-to-CMM data interoperability when using STEP AP242 with embedded PMI. In doing so, there were many issues uncovered, some we were able to address within the project and others require further effort to overcome. Some significant gaps were identified as well. These gaps will need to be addressed through changes in the tools, standards, and processes used currently to share information from design to manufacturing and inspection across the supply chain.

${ }^{14}$ International Aerospace Quality Group. (2014, October 06). AS9102B. Aerospace First Article Inspection Requirements. SAE International. 
Investigating the Impact of Standards-Based Interoperability for Design to Manufacturing and Quality

\section{Acknowledgements}

The team would first like to recognize the NIST System Integration Division, Engineering Laboratory, for providing this project opportunity. The Digital Thread is an important concept for industry. NIST focus and investment in product lifecycle capabilities and standards is truly recognized. Especially, we thank Allison Barnard Feeney and Thomas Hedberg, Jr. who have provided the leadership in establishing the Digital Thread for Smart Manufacturing. The project team fully supports the drive to investigate the product lifecycle holistically and extend the digital thread of information with easy implementation into manufacturing systems. NIST has provided a significant seed opportunity for commercialization of standards-based model-centric data interoperability - enabling industry's vision of the Model-Based Enterprise.

A project like this would not be possible without the commitment and contributions from a number people. The project team would like to acknowledge the following companies and individuals who participated in various elements of the grant.

ACCR, Inc., Summerville, SC, provided consulting and project management services for the program. Phil Rosche of ACCR contributed to project planning, insights into the current and expected near-term states of the ISO10303 STEP standard, and assisted in keeping project work on track. Phil contributed significantly to authoring of the final report.

Rockwell Collins, Cedar Rapids, IA, provided the industry OEM perspective for the project. Rockwell Collins was the principal host for the kick-off and planning meeting as well as the final demonstration meeting. Tom Matuska and Jesse Pisarik were responsible for selection of representative Rockwell Collins parts, transformation of the Rockwell Collins designs from traditional model and drawing sets into 3D models with embedded PMI. Tom and Jesse also collected metrics data for the current-state and future-state design processes. They helped write and edit the sections on model selection. Scott Wegener supported the supply chain process discussions and provided insight into the issues associated with aerospace and defense supply chain traceability and practices. Kevin Fischer led the Rockwell Collins team and was responsible for metrics definition and data analysis. He contributed valuable insight into design for manufacture and manufacturing processes. Kevin contributed significantly to authoring of the final report.

Geater Machining and Manufacturing, Independence, IA, a manufacturing supplier to Rockwell Collins, was responsible for manufacturing operations and downstream manufacturing and inspection processes for the selected test parts. They were the secondary host for the kick-off and planning meeting as well as the final demonstration meeting. Geater collected the downstream metrics data. Greg Sondag, Programming Engineer Supervisor, was the project lead for Geater. He was responsible for manufacturing planning and execution as well as manufacturing metrics data collection and analysis for CAM processes. Derrick Hess, Quality Working Supervisor, was responsible for manufacturing inspection processes as well as metrics data collection and analysis for those processes. Greg and Derrick helped write the sections on CAM and CMM processes. 
Investigating the Impact of Standards-Based Interoperability for Design to Manufacturing and Quality

CT CoreTechnologie, Southfield, MI, and Lyon, France, was responsible for writing algorithms to extract PMI presentation and representation data from the CAD models and the output of the data into STEP AP242 format. David Selliman led the US team and Guillaume Blanchard led the algorithm development in Europe.

CNC Software, Inc, Tolland, CT, provided the Mastercam manufacturing planning and execution software for the project. Pete Rimkus, Product Owner, CAD Interfaces, was responsible for developing algorithms to load semantic PMI content into the Mastercam manufacturing planning software.

Mitutoyo America Corporation, Aurora, IL, provided the MiCAT metrology planning software for the project. Larry Maggiano, Senior Systems Analyst, was responsible for analyzing the consumption of eACIS data structures converted from STEP AP242 data by the MiCAT Planner and leveraging those characteristics in the metrology planning process. Larry provided CMM subject matter expertise and guidance on metrology standards and processes. Larry also provided metrology-focused requirements for future systems.

International TechneGroup Incorporated, Milford, $\mathrm{OH}$, provided overall program execution and grant administration as well as technical development of translation components. Ed Paff was responsible for translation component development. Asa Trainer, VP of Product Operations, was responsible for program execution administration. Asa contributed significantly to authoring of the final report. 
Investigating the Impact of Standards-Based Interoperability for Design to Manufacturing and Quality

Works Cited

American Society of Mechanical Engineers. (n.d.). Y14.41.1. 3D Model Data Organization Schema (in development). ASME.

Hartman, N., Fischer, K., \& Rosche, P. (May 21-23, 2012). Successfully Engaging Small and Medium Enterprises. 3D Collaboration and Interoperability Congress. Englewood, CO.

Hedberg, Jr., T., Lubell, J., Fischer, L., Maggiano, L., \& Barnard Feeney, A. (2015). Testing the Digital Thread in Support of Model-Based Manufacturing and Inspection. Submitted for publication.

International Aerospace Quality Group . (2014, October 06). AS9102B. Aerospace First Article Inspection Requirements. SAE International.

ISO/TC 184/SC 4. (1994, December 15). ISO 10303-1:1994. Industrial automation systems and integration -- Product data representation and exchange -- Part 1: Overview and fundamental principles. International Organization for Standardization.

NIST Collaborative Agreement: 70NANB14H256. (2105). Validation for Downstream Computer Aided Manufacturing and Coordinate Metrology Processes.

NIST MEP. (November 22, 2009). Phase One Final Report - Assessment of Supplier Capabilities to Operate in a Model-Based Environment.

PDES, Inc. and ProSTEP iViP. (n.d.). CAx Implementor Forum. Retrieved October 09, 2015, from https://cax-if.org/index.html

Spatial Corp. (n.d.). 3D ACIS Modeling. Retrieved October 09, 2015, from Spatial Products: http://www.spatial.com/products/3d-acis-modeling

United States Department of Defense. (2011, April). Technology Readiness Review Assessment (TRA) Guidance. Retrieved October 09, 2015, from http://www.acq.osd.mil/chieftechnologist/publications/docs/TRA2011.pdf

United States Department of Defense. (2013, February 26). MIL-STD-31000A. Department of Defense Standard Practice: Technical Data Packages. 
Investigating the Impact of Standards-Based Interoperability for Design to Manufacturing and Quality

Appendices

\section{Appendix A: Use Cases}

\section{Visualization and Collaboration Use Cases}

Two use cases that will require significant change from current state to the future state processes following the introduction of embedded-PMI models are visualization (human-interpretable presentation) and collaboration. The need to visualize and collaborate is prevalent for both the OEM and Supplier with many of the identified use cases. For instance, it is anticipated that 3D PDF (or a similar format) will serve as a likely visualization tool to capture and display embedded information within a model. Likewise, how the OEM and supplier collaborate, whether for bidding and quoting, addressing discrepancies, or incorporating engineering changes will need to be different than how it is done today when using 2D drawings and mark-ups. These use cases are out of scope with this project.

\section{OEM Use Cases}

\section{CAD Model Creation}

This use case centers on the creation or authoring of the CAD model. Traditionally, the 3D-shapegeometry model is created without embedded PMI. Once the shape-geometry model is generated, a 2D drawing is created, and typically presented in 2D PDF format. It includes the PMI that is not part of the 3D-shape-geometry model. In the past, the 2D drawing was fully detailed and could be used by itself to manufacture the part. In more recent practice, a 3D-shape-geometry model and a 2D-partial-dimension drawing are required. The partial-dimension drawing contains only the PMI that is not embedded in the shape model. In the current-state scenarios either the full-detail drawing or the combination of the shape model and the partial-detail drawing is required for manufacturing processes. In the future-state process designers will create a 3D model with embedded PMI such that the model will completely support the manufacturing and inspection processes. This use case was used in the scope of this project.

\section{CAD Model Validation}

In this use case the current process is to manually inspect the 2D drawing and the 3D model separately when providing a producibility review or performing a check in preparation of design release into the PDM system. This relies entirely on the experience and ability of the operator to review the drawing or visually interpret the model. With embedded PMI the reviewer will need the capability to visualize and inspect the information in the 3D model. In the future, 3D models with the embedded PMI will lend themselves to more automated producibility and check (validation) tools. This automation, in turn, could enable in-process reviews to occur sooner and with more frequency than just when a designer submits work to a producibility engineer or checker near the release point for a design. This future state use case was not directly investigated as part of this project. But, during the project, metrics were captured that indicate gaps in tools and knowledge that must be overcome in order to properly embed $\mathrm{PMI}$ in a design model so that it is ready for consumption by downstream systems. This also amplifies the need for and importance of a model validation capability and tools. 
Investigating the Impact of Standards-Based Interoperability for Design to Manufacturing and Quality

Part Procurement (Bid Request; Supplier Portal)

The current practice is to provide the supplier with a 3D model (typically native CAD or STEP AP203 format) and a 2D drawing (PDF format) with the PMI not embedded in model. The information may be accessible through a supply chain portal at the OEM that allows the supplier to directly access both models and drawings. In the future, the 3D model with embedded PMI will be available through the same supply chain portal process. A 3D PDF (or equivalent) could also be provided for visualization as well as provide an integrated STEP file attachment for the supplier to access through the portal. This use case is out of scope for this project but should be explored in future work.

Engineering Changes (Request/Mark-up; Validation; Documentation) Currently a change request requires the mark-up of a 2D drawing. Once the change is accepted and an ECO completed, the model and drawing updates are validated against the mark-up and the change order is provided to the supplier for implementation. This process creates opportunity for error in correctly converting the mark-up into the model. In the future, a process to address mark-up as well as convey the approved change in a full model-based approach will need to be determined. Several approaches have been demonstrated or discussed. This use case is out of scope for this project but should be addressed as industry moves to a complete model based enterprise.

Part Receiving Inspection

Today receiving inspection is completed using the 2D drawing. Parts are received from the supplier, along with the First Article Inspection Report (FAIR), which is typically provided in spreadsheet format. Receiving inspectors verify the report and check a portion of the part dimensions for consistency. In the future, when PMI is fully embedded in the 3D model, the receiving inspection process will require ability to utilize a format such as 3D PDF for visualization during part receiving inspection. This use case is out of scope for this project. There is opportunity to couple the development from this project with that of another ongoing NIST project to demonstrate the impact of model-centric data interoperability with first article inspection reporting and receiving inspection using the Quality Information Framework (QIF). ${ }^{15}$

\section{Assembly Work Instructions}

When a design is transformed into assembly work instructions, the 2D drawing is often used in the construction of those instructions. Assembly and manufacturing resource information associated with a particular route step is added alongside the 2D drawing for operators to follow the correct assembly process steps. In the future, a 3D visualization will replace the 2D drawing as part of the work instruction construct. This offers a more immersive experience as well as introduces other technologies to provide work instruction aids to the operators. This use case is out of scope for this project.

\section{Technical Data Package Delivery (from OEM to Customer)}

Today TDP delivery from an OEM to a customer is typically satisfied with 2D drawings. These may be augmented upon contract request with native CAD or STEP AP203 3D models. In the future, 3D models

\footnotetext{
${ }^{15}$ NIST Collaborative Agreement: 70NANB14H256. (2015). Validation for Downstream Computer Aided Manufacturing and Coordinate Metrology Processes.
} 
Investigating the Impact of Standards-Based Interoperability for Design to Manufacturing and Quality and 3D visualization artifacts are expected to be the primary basis for TDP delivery per MIL-STD-31000A. This use case is out of scope for this project but should be explored in related and future work.

\section{Supplier Use Cases}

Bid or Quote Process

Currently a supplier will use 2D drawings to provide a bid or quote. There is more estimation involved in the process when only a drawing is available. The opportunity to use a 3D model and associated 3D visualization file provides much more information and could even allow for some automated bidding tools. This use case is out of scope for this project, but some anecdotal insight may be provided as part of the findings.

\section{CAM Model Creation}

The CAM-programming use case focuses on the import of a STEP AP203 model for the shape-geometry. The 2D drawing is referenced for the PMI not embedded in the model. In addition, the manufacturing specifications that are referenced in the drawing are also reviewed to determine additional machine programming and secondary operations. It is difficult to envision what changes in the CAM modeling process will be introduced with the use of models with embedded PMI. There should be reduced risk of error between CAD and CAM models, and there may be improved ability to automate the validation of CAD model to CAM model. This use case is within scope of the project.

\section{CAM Work Instruction Creation}

Currently the 3D CAD model, usually in STEP AP203 format, and the manufacturing specifications referenced in the 2D drawing are used by the supplier to create part manufacturing work instructions. Starting with these artifacts, the actual instructions and graphics for each route step is created. It is anticipated that the future use case will remain similar but, it will require less reference to drawing specifications. This use case is out of scope for this project, but some anecdotal insight may be provided as part of the findings.

\section{In-Process Part Inspection}

Currently, the supplier will perform in-process inspection of a part to determine that certain dimensional aspects are correct before proceeding with the next steps of part manufacturing. This is accomplished by referencing the 2D drawing as well as the STEP AP203 model for information against which to inspect the part. Sometimes discrepancies between the CAD model and the drawing are discovered at this point. The future state with embedded PMI should offer less risk of discrepancy than might occur between the model and drawing. This use case will be out of scope for the project, but some anecdotal insight may be provided as part of the findings.

\section{CMM Model Creation}

The CMM-model use case utilizes the 2D drawing and the STEP AP203 model to create the CMM model. All the $\mathrm{PMI}$ is manually entered into the $\mathrm{CMM}$ application. The future state will directly import the embedded PMI from a STEP AP242 model, providing significant automation of data entry into the CMM system. Like the CAM programming, CMM model creation and machine programming provides a basis of measurement for the project. 
Investigating the Impact of Standards-Based Interoperability for Design to Manufacturing and Quality

CMM Inspection and First Article Inspection Report

The CMM-inspection use case involves a significantly manual process to generate the First Article Inspection Report. The anticipated future state enables a much more automated process. The inspection metrics will be captured in the project and will provide insight into the benefits possible for automating first article reporting. This use case is also explored in another NIST project involving the Quality Information Framework (QIF). ${ }^{16}$

\section{Engineering Changes (Request/Mark-up; Validation; Documentation)}

Today a change request requires the mark-up of a 2D drawing. Once the change is accepted and an ECO completed, the model and drawing changes are validated against the mark-up and the change order is provided to the supplier for implementation. This process creates opportunity for error in correctly converting the mark-up into the model. In the future, a method to address mark-up as well as convey the change in a model based approach will need to be determined. Several approaches have been demonstrated or discussed. This use case is out of scope for this project but should be addressed for industry to move to a complete model based enterprise.

Table 12: Product lifecycle use case metrics

\begin{tabular}{|c|c|c|c|c|c|}
\hline \multirow[b]{2}{*}{ Use Cases } & \multicolumn{4}{|c|}{ Metrics } & \multirow[b]{2}{*}{ Relative to Project Scope } \\
\hline & $\begin{array}{l}\text { Cycle } \\
\text { Time }\end{array}$ & $\begin{array}{l}\text { Model } \\
\text { Quality }\end{array}$ & $\begin{array}{c}\text { Part } \\
\text { Quality }\end{array}$ & Cost & \\
\hline \multicolumn{6}{|l|}{ at OEM } \\
\hline CAD Model Creation & $\mathrm{x}$ & $x$ & & & will be demonstrated \\
\hline Model Validation (Producibility; Check; Release) & $\mathrm{x}$ & $\mathrm{x}$ & & $\mathrm{x}$ & will be demonstrated \\
\hline Part Procurement (Bid Request; Supplier Portal) & $\mathrm{x}$ & & & $\mathrm{x}$ & out of scope \\
\hline Receiving Inspection & $\mathrm{x}$ & & $\mathrm{x}$ & & out of scope / possible anecdotal insight \\
\hline Assembly Work Instructions & & & & & out of scope \\
\hline Technical Data Package Delivery (to Customer) & & & & & out of scope \\
\hline Engineering Change & $\mathrm{x}$ & $\mathrm{X}$ & $\mathrm{X}$ & & out of scope \\
\hline \multicolumn{6}{|l|}{ at Supplier } \\
\hline Bid or Quote Process & $\mathrm{x}$ & & & $\mathrm{X}$ & out of scope / possible anecdotal insight \\
\hline CAM Programming & $\mathrm{x}$ & $\mathrm{x}$ & & & will be demonstrated \\
\hline Work Instruction Creation & $\mathrm{x}$ & & $\mathrm{x}$ & & may be out of scope \\
\hline In-Process Inspection & $\mathrm{x}$ & & $\mathrm{x}$ & & out of scope / possible anecdotal insight \\
\hline CMM Programming & $\mathrm{x}$ & $\mathrm{X}$ & & & will be demonstrated \\
\hline CMM Inspection and FAI Report & $\mathrm{x}$ & & $\mathrm{x}$ & & will be demonstrated \\
\hline Engineering Change & $x$ & $x$ & $x$ & & out of scope \\
\hline
\end{tabular}

\section{Appendix B: Mapping PMI into STEP and ACIS}

Appendix B.1: Mapping GD\&T into STEP and ACIS

\begin{tabular}{|l|l|l|}
\hline PMI & STEP AP242 & ACIS \\
\hline dimension types & & \\
\hline linear dimension & dimensional_location & spaxpmi_dimension \\
\hline angular dimension & angular_location/angular_size & $\begin{array}{l}\text { spaxpmi_dimension } \\
\text { (no way to specify which angle) }\end{array}$ \\
\hline
\end{tabular}

\footnotetext{
${ }^{16}$ NIST Collaborative Agreement: 70NANB14H256. (2015). Validation for Downstream Computer Aided Manufacturing and Coordinate Metrology Processes.
} 
Investigating the Impact of Standards-Based Interoperability for Design to Manufacturing and Quality

\begin{tabular}{|c|c|c|}
\hline PMI & STEP AP242 & ACIS \\
\hline radius dimension & dimensional_size.name = "radius" & spaxpmi_dimension \\
\hline $\begin{array}{l}\text { spherical radius } \\
\text { dimension }\end{array}$ & dimensional_size.name = "spherical radius" & not covered \\
\hline diameter dimension & dimensional_size.name = "diameter" & spaxpmi_dimension \\
\hline $\begin{array}{l}\text { spherical diameter } \\
\text { dimension }\end{array}$ & dimensional_size.name = "spherical diameter" & not covered \\
\hline oriented dimension & oriented_dimensional_location & not covered \\
\hline curved dimension & dimensional_location_with_path / dimensional_size_with_path & not covered \\
\hline \multicolumn{3}{|l|}{$\begin{array}{l}\text { dimension } \\
\text { tolerance principle }\end{array}$} \\
\hline independency & shape_dimension_representation.name = "independency" & not covered \\
\hline envelope & shape_dimension_representation.name = "envelope" & not covered \\
\hline \multicolumn{3}{|l|}{ dimension values } \\
\hline nominal value & measure_representation_item.name = "nominal value" & dimension value \\
\hline $\begin{array}{l}\text { nominal value with } \\
\text { qualifier }\end{array}$ & qualified_representation_item & not covered \\
\hline $\begin{array}{l}\text { nominal value with plus / } \\
\text { minus bounds }\end{array}$ & plus_minus_tolerance & not covered \\
\hline value range & $\begin{array}{l}\text { measure_representation_item.name = "upper limit" / "lower } \\
\text { limit" }\end{array}$ & $\begin{array}{l}\text { dimtol lower limit } \\
\text { dimtol upper limit }\end{array}$ \\
\hline tolerance class & limits_and_fits & not covered \\
\hline \multicolumn{3}{|l|}{$\begin{array}{l}\text { dimension } \\
\text { modifiers }\end{array}$} \\
\hline basic / theoretical & descriptive_representation_item.description = "theoretical" & $\begin{array}{l}\text { dimension_type } \\
\text { (dimtype_basic) }\end{array}$ \\
\hline reference / auxiliary & descriptive_representation_item.description = "auxiliary" & $\begin{array}{l}\text { dimension_type } \\
\text { (dimtype_reference) }\end{array}$ \\
\hline controlled radius & $\begin{array}{l}\text { descriptive_representation_item.description = "controlled } \\
\text { radius" }\end{array}$ & not covered \\
\hline square & descriptive_representation_item.description = "square" & not covered \\
\hline statistical tolerance & $\begin{array}{l}\text { descriptive_representation_item.description = "statistical } \\
\text { tolerance" }\end{array}$ & $\begin{array}{l}\text { dimension_type } \\
\text { (dimtype_tolerance) }\end{array}$ \\
\hline continuous feature & $\begin{array}{l}\text { descriptive_representation_item.description = "continuous } \\
\text { feature" }\end{array}$ & not covered \\
\hline two point size & descriptive_representation_item.description = "two point size" & not covered \\
\hline $\begin{array}{l}\text { local size defined by a } \\
\text { sphere }\end{array}$ & $\begin{array}{l}\text { descriptive_representation_item.description = "local size defined } \\
\text { by sphere" }\end{array}$ & not covered \\
\hline $\begin{array}{l}\text { least-squares association } \\
\text { criterion }\end{array}$ & $\begin{array}{l}\text { descriptive_representation_item.description = "least-squares } \\
\text { association criterion" }\end{array}$ & not covered \\
\hline $\begin{array}{l}\text { maximum inscribed } \\
\text { association criterion }\end{array}$ & $\begin{array}{l}\text { descriptive_representation_item.description = "maximum } \\
\text { inscribed association criterion" }\end{array}$ & not covered \\
\hline $\begin{array}{l}\text { minimum inscribed } \\
\text { association criterion }\end{array}$ & $\begin{array}{l}\text { descriptive_representation_item.description = "minimum } \\
\text { inscribed association criterion" }\end{array}$ & not covered \\
\hline circumference diameter & $\begin{array}{l}\text { descriptive_representation_item.description = "circumference } \\
\text { diameter" }\end{array}$ & not covered \\
\hline area diameter & descriptive_representation_item.description = "area diameter" & not covered \\
\hline volume diameter & $\begin{array}{l}\text { descriptive_representation_item.description = "volume } \\
\text { diameter" }\end{array}$ & not covered \\
\hline maximum size & descriptive_representation_item.description = "maximum size" & not covered \\
\hline
\end{tabular}


Investigating the Impact of Standards-Based Interoperability for Design to Manufacturing and Quality

\begin{tabular}{|c|c|c|}
\hline PMI & STEP AP242 & ACIS \\
\hline minimum size & descriptive_representation_item.description = "minimum size" & not covered \\
\hline average size & descriptive_representation_item.description = "average size" & not covered \\
\hline median size & descriptive_representation_item.description = "median size" & not covered \\
\hline mid-range size & descriptive_representation_item.description = "mid-range size" & not covered \\
\hline range of sizes & descriptive_representation_item.description = "range of sizes" & not covered \\
\hline $\begin{array}{l}\text { any restricted portion of } \\
\text { feature }\end{array}$ & $\begin{array}{l}\text { descriptive_representation_item.description = "any restricted } \\
\text { portion of feature" }\end{array}$ & not covered \\
\hline any cross section & $\begin{array}{l}\text { descriptive_representation_item.description = "any cross } \\
\text { section" }\end{array}$ & not covered \\
\hline $\begin{array}{l}\text { specific fixed cross } \\
\text { section }\end{array}$ & $\begin{array}{l}\text { descriptive_representation_item.description = "specific fixed } \\
\text { cross section" }\end{array}$ & not covered \\
\hline common tolerance & $\begin{array}{l}\text { descriptive_representation_item.description = "common } \\
\text { tolerance" }\end{array}$ & not covered \\
\hline free-state condition & $\begin{array}{l}\text { descriptive_representation_item.description = "free-state } \\
\text { condition" }\end{array}$ & not covered \\
\hline $\begin{array}{l}\text { dimension decimal } \\
\text { places }\end{array}$ & value_format_type_qualifier & dimtol precision \\
\hline datum & datum & spaxpmi_datum \\
\hline datum feature & datum_feature & attrib_spaxpmi_datum \\
\hline datum target & placed_datum_target_feature & spaxpmi_datumtgt \\
\hline point & axis2_placement_3d.name = "orientation" & datum_target_type (dt_point) \\
\hline line & $\begin{array}{l}\text { axis2_placement_3d / length_measure_with_unit.name = "target } \\
\text { length" }\end{array}$ & datum_target_type (dt_line) \\
\hline rectangle & $\begin{array}{l}\text { axis2_placement_3d / length_measure_with_unit.name = "target } \\
\text { width" }\end{array}$ & $\begin{array}{l}\text { datum_target_type } \\
\text { (dt_area_rect) }\end{array}$ \\
\hline circle & $\begin{array}{l}\text { axis2_placement_3d/length_measure_with_unit.name = "target } \\
\text { diameter" }\end{array}$ & $\begin{array}{l}\text { datum_target_type } \\
\text { (dt_area_circ) }\end{array}$ \\
\hline area & advanced_face & $\begin{array}{l}\text { datum_target_type } \\
\text { (dt_area_face) }\end{array}$ \\
\hline movable datum target & Direction & not covered \\
\hline tolerance & geometric_tolerance & attrib_spaxpmi_geom_tol \\
\hline \multicolumn{3}{|l|}{ tolerance types } \\
\hline angularity & angularity_tolerance & tol_type (toltype_angularity) \\
\hline circular runout & circular_runout_tolerance & $\begin{array}{l}\text { tol_type } \\
\text { (toltype_runout_circular) }\end{array}$ \\
\hline circularity / roundness & roundness_tolerance & tol_type (toltype_circularity) \\
\hline coaxiality & coaxiality_tolerance & not covered \\
\hline concentricity & concentricity_tolerance & $\begin{array}{l}\text { tol_type } \\
\text { (toltype_concentricity) }\end{array}$ \\
\hline cylindricity & cylindricity_tolerance & tol_type (toltype_cylindricity) \\
\hline flatness & flatness_tolerance & tol_type (toltype_flatness) \\
\hline parallelism & parallelism_tolerance & tol_type (toltype_parallelism) \\
\hline perpendicularity & perpendicularity_tolerance & $\begin{array}{l}\text { tol_type } \\
\text { (toltype_perpendicularity) }\end{array}$ \\
\hline position & position_tolerance & tol_type (toltype_position) \\
\hline profile of a line & line_profile_tolerance & tol_type (toltype_profile_line) \\
\hline profile of a surface & surface_profile_tolerance & tol_type (toltype_profile_surf) \\
\hline
\end{tabular}


Investigating the Impact of Standards-Based Interoperability for Design to Manufacturing and Quality

\begin{tabular}{|c|c|c|}
\hline PMI & STEP AP242 & ACIS \\
\hline straightness & straightness_tolerance & tol_type (toltype_straightness) \\
\hline symmetry & symmetry_tolerance & tol_type (toltype_symmetry) \\
\hline total runout & total_runout_tolerance & $\begin{array}{l}\text { tol_type } \\
\text { (toltype_runout_total) }\end{array}$ \\
\hline \multicolumn{3}{|l|}{ tolerance zone } \\
\hline diameter & tolerance_zone_form.name = "cylindrical or circular" & mod_dia_type (dm_dia) \\
\hline spherical diameter & tolerance_zone_form.name = "spherical" & $\begin{array}{l}\text { mod_dia_type } \\
\text { (dm_spherical_dia) }\end{array}$ \\
\hline within a circle & tolerance_zone_form.name = "within a circle" & not covered \\
\hline $\begin{array}{l}\text { between two concentric } \\
\text { circles }\end{array}$ & tolerance_zone_form.name = "between two concentric circles" & not covered \\
\hline $\begin{array}{l}\text { between two equidistant } \\
\text { curves }\end{array}$ & tolerance_zone_form.name = "between two equidistant curves" & not covered \\
\hline within a cylinder & tolerance_zone_form.name = "within a cylinder" & not covered \\
\hline $\begin{array}{l}\text { between two coaxial } \\
\text { cylinders }\end{array}$ & tolerance_zone_form.name = "between two coaxial cylinders" & not covered \\
\hline $\begin{array}{l}\text { between two equidistant } \\
\text { surfaces }\end{array}$ & $\begin{array}{l}\text { tolerance_zone_form.name = "between two equidistant } \\
\text { surfaces" }\end{array}$ & not covered \\
\hline runout & runout_zone_definition & not covered \\
\hline projected & projected_zone_definition & p_mag \\
\hline non-uniform & non_uniform_zone_definition & not covered \\
\hline \multicolumn{3}{|l|}{ tolerance modifiers } \\
\hline any cross section & $\begin{array}{l}\text { geometric_tolerance_with_modifiers.modifiers = } \\
\text {.ANY_CROSS_SECTION. }\end{array}$ & not covered \\
\hline common zone & $\begin{array}{l}\text { geometric_tolerance_with_modifiers.modifiers = } \\
\text {.COMMON_ZONE. }\end{array}$ & not covered \\
\hline each radial element & $\begin{array}{l}\text { geometric_tolerance_with_modifiers.modifiers = } \\
\text {.EACH_RADIAL_ELEMENT. }\end{array}$ & not covered \\
\hline free state & geometric_tolerance_with_modifiers.modifiers $=$.FREE_STATE. & zone_modifier_type (zm_fs) \\
\hline $\begin{array}{l}\text { least material } \\
\text { requirement }\end{array}$ & $\begin{array}{l}\text { geometric_tolerance_with_modifiers.modifiers = } \\
\text {.LEAST_MATERIAL_REQUIREMENT. }\end{array}$ & zone_modifier_type (zm_Imc) \\
\hline line element & $\begin{array}{l}\text { geometric_tolerance_with_modifiers.modifiers = } \\
\text {.LINE_ELEMENT. }\end{array}$ & not covered \\
\hline major diameter & $\begin{array}{l}\text { geometric_tolerance_with_modifiers.modifiers = } \\
\text {.MAJOR_DIAMETER. }\end{array}$ & not covered \\
\hline $\begin{array}{l}\text { maximum material } \\
\text { requirement }\end{array}$ & $\begin{array}{l}\text { geometric_tolerance_with_modifiers.modifiers = } \\
\text {.MAXIMUM_MATERIAL_REQUIREMENT. }\end{array}$ & zone_modifier_type (zm_mmc) \\
\hline minor diameter & $\begin{array}{l}\text { geometric_tolerance_with_modifiers.modifiers = } \\
\text {.MINOR_DIAMETER. }\end{array}$ & not covered \\
\hline not convex & geometric_tolerance_with_modifiers.modifiers = .NOT_CONVEX. & not covered \\
\hline pitch diameter & $\begin{array}{l}\text { geometric_tolerance_with_modifiers.modifiers = } \\
\text {.PITCH_DIAMETER. }\end{array}$ & not covered \\
\hline reciprocity requirement & $\begin{array}{l}\text { geometric_tolerance_with_modifiers.modifiers = } \\
\text {.RECIPROCITY_REQUIREMENT. }\end{array}$ & zone_modifier_type (zm_rfs) \\
\hline separate requirement & $\begin{array}{l}\text { geometric_tolerance_with_modifiers.modifiers = } \\
\text {.SEPARATE_REQUIREMENT. }\end{array}$ & not covered \\
\hline statistical tolerance & $\begin{array}{l}\text { geometric_tolerance_with_modifiers.modifiers = } \\
\text {.STATISTICAL_TOLERANCE. }\end{array}$ & zone_modifier_type (zm_st) \\
\hline tangent plane & $\begin{array}{l}\text { geometric_tolerance_with_modifiers.modifiers = } \\
\text {.TANGENT_PLANE. }\end{array}$ & zone_modifier_type (zm_tp) \\
\hline
\end{tabular}


Investigating the Impact of Standards-Based Interoperability for Design to Manufacturing and Quality

\begin{tabular}{|c|c|c|}
\hline PMI & STEP AP242 & ACIS \\
\hline $\begin{array}{l}\text { unequally-disposed } \\
\text { tolerance }\end{array}$ & unequally_disposed_geometric_tolerance & p_shift \\
\hline $\begin{array}{l}\text { tolerance with maximum } \\
\text { value }\end{array}$ & geometric_tolerance_with_maximum_tolerance & not covered \\
\hline \multicolumn{3}{|l|}{ unit-basis tolerance } \\
\hline length & geometric_tolerance_with_defined_unit & runit1 \\
\hline circular & $\begin{array}{l}\text { geometric_tolerance_with_defined_area_unit.area_type = } \\
\text {.CIRCULAR. }\end{array}$ & runit1 \\
\hline rectangular & $\begin{array}{l}\text { geometric_tolerance_with_defined_area_unit.area_type = } \\
\text {.RECTANGULAR. }\end{array}$ & runit1,runit2 \\
\hline square & $\begin{array}{l}\text { geometric_tolerance_with_defined_area_unit.area_type = } \\
\text {.SQUARE. }\end{array}$ & runit1 \\
\hline composite tolerance & geometric_tolerance_relationship & attrib_spaxpmi_geom_tol \\
\hline $\begin{array}{l}\text { tolerance with datum } \\
\text { references }\end{array}$ & geometric_tolerance_with_datum_reference & spaxpmi_drf \\
\hline datum reference & datum_reference_compartment & spaxpmi_dref \\
\hline \multicolumn{3}{|l|}{$\begin{array}{l}\text { datum reference } \\
\text { modifiers }\end{array}$} \\
\hline free state & simple_datum_reference_modifier.modifiers $=$. FREE_STATE. & not covered \\
\hline basic & simple_datum_reference_modifier.modifiers $=$. BASIC. & not covered \\
\hline translation & simple_datum_reference_modifier.modifiers $=$.TRANSLATION. & not covered \\
\hline $\begin{array}{l}\text { least material } \\
\text { requirement }\end{array}$ & $\begin{array}{l}\text { simple_datum_reference_modifier.modifiers = } \\
\text {.LEAST_MATERIAL_REQUIREMENT. }\end{array}$ & $\begin{array}{l}\text { datum_modifier_type } \\
\text { (datum_modifier_Imc) }\end{array}$ \\
\hline $\begin{array}{l}\text { maximum material } \\
\text { requirement }\end{array}$ & $\begin{array}{l}\text { simple_datum_reference_modifier.modifiers = } \\
\text {.MAXIMUM_MATERIAL_REQUIREMENT. }\end{array}$ & $\begin{array}{l}\text { datum_modifier_type } \\
\text { (datum_modifier_mmc) }\end{array}$ \\
\hline point & simple_datum_reference_modifier.modifiers = .POINT. & not covered \\
\hline line & simple_datum_reference_modifier.modifiers = .LINE. & not covered \\
\hline plane & simple_datum_reference_modifier.modifiers = .PLANE. & not covered \\
\hline orientation & simple_datum_reference_modifier.modifiers $=$. ORIENTATION. & not covered \\
\hline any cross section & $\begin{array}{l}\text { simple_datum_reference_modifier.modifiers = } \\
\text {.ANY_CROSS_SECTION. }\end{array}$ & not covered \\
\hline any longitudinal section & $\begin{array}{l}\text { simple_datum_reference_modifier.modifiers = } \\
\text {.ANY_LONGITUDINAL_SECTION. }\end{array}$ & not covered \\
\hline contacting feature & $\begin{array}{l}\text { simple_datum_reference_modifier.modifiers = } \\
\text {.CONTACTING_FEATURE. }\end{array}$ & not covered \\
\hline distance variable & $\begin{array}{l}\text { simple_datum_reference_modifier.modifiers = } \\
\text {.DISTANCE_VARIABLE. }\end{array}$ & not covered \\
\hline $\begin{array}{l}\text { degree of freedom } \\
\text { constraint } x\end{array}$ & $\begin{array}{l}\text { simple_datum_reference_modifier.modifiers = } \\
\text {.DEGREE_OF_FREEDOM_CONSTRAINT_X. }\end{array}$ & not covered \\
\hline $\begin{array}{l}\text { degree of freedom } \\
\text { constraint } y\end{array}$ & $\begin{array}{l}\text { simple_datum_reference_modifier.modifiers = } \\
\text {.DEGREE_OF_FREEDOM_CONSTRAINT_Y. }\end{array}$ & not covered \\
\hline $\begin{array}{l}\text { degree of freedom } \\
\text { constraint } z\end{array}$ & $\begin{array}{l}\text { simple_datum_reference_modifier.modifiers = } \\
\text {.DEGREE_OF_FREEDOM_CONSTRAINT_Z. }\end{array}$ & not covered \\
\hline $\begin{array}{l}\text { degree of freedom } \\
\text { constraint } u\end{array}$ & $\begin{array}{l}\text { simple_datum_reference_modifier.modifiers = } \\
\text {.DEGREE_OF_FREEDOM_CONSTRAINT_U. }\end{array}$ & not covered \\
\hline $\begin{array}{l}\text { degree of freedom } \\
\text { constraint } v\end{array}$ & $\begin{array}{l}\text { simple_datum_reference_modifier.modifiers = } \\
\text {.DEGREE_OF_FREEDOM_CONSTRAINT_V. }\end{array}$ & not covered \\
\hline $\begin{array}{l}\text { degree of freedom } \\
\text { constraint } w\end{array}$ & $\begin{array}{l}\text { simple_datum_reference_modifier.modifiers = } \\
\text {.DEGREE_OF_FREEDOM_CONSTRAINT_W. }\end{array}$ & not covered \\
\hline
\end{tabular}


Investigating the Impact of Standards-Based Interoperability for Design to Manufacturing and Quality

\begin{tabular}{|c|c|c|}
\hline PMI & STEP AP242 & ACIS \\
\hline minor diameter & $\begin{array}{l}\text { simple_datum_reference_modifier.modifiers = } \\
\text {.MINOR_DIAMETER. }\end{array}$ & not covered \\
\hline major diameter & $\begin{array}{l}\text { simple_datum_reference_modifier.modifiers = } \\
\text {.MAJOR_DIAMETER. }\end{array}$ & not covered \\
\hline pitch diameter & $\begin{array}{l}\text { simple_datum_reference_modifier.modifiers = } \\
\text {.PITCH_DIAMETER. }\end{array}$ & not covered \\
\hline with value & datum_reference_modifier_with_value & not covered \\
\hline $\begin{array}{l}\text { common datum/multiple } \\
\text { datum features }\end{array}$ & datum_reference_element & spaxpmi_dref \\
\hline polyline presentation & $\begin{array}{l}\text { annotation_curve_occurrence / annotation_fill_area_occurrence } \\
\text { / annotation_symbol_occurrence / } \\
\text { annotation_text_occurrence/tessellated_annotation_occurrence }\end{array}$ & body/wire \\
\hline \multicolumn{3}{|l|}{ BREP } \\
\hline \multicolumn{3}{|l|}{ topology } \\
\hline solid & manifold_solid_brep & body/lump \\
\hline shell & closed_shell / open_shell & shell \\
\hline face & advanced_face & face \\
\hline loop & face_bound / face_outer_bound / edge_loop / vertex_loop & loop \\
\hline edge & oriented_edge / edge_curve & edge/coedge \\
\hline vertex & vertex_point / cartesian_point & vertex \\
\hline \multicolumn{3}{|l|}{ surface geometry } \\
\hline cone & conical_surface & cone \\
\hline cylinder & cylindrical_surface & cone \\
\hline extruded surface & surface_of_linear_extrusion & spline \\
\hline nurbs & $\begin{array}{l}\text { b_spline_surface / b_spline_surface_with_knots / } \\
\text { rational_b_spline_surface / uniform_surface / } \\
\text { quasi_uniform_surface / bezier_surface }\end{array}$ & spline \\
\hline offset surface & offset_surface & off_spl_sur \\
\hline plane & planar_surface & plane \\
\hline revolved surface & surface_of_revolution & rot_spl_sur \\
\hline sphere & spherical_surface & sphere \\
\hline torus & toroidal_surface & torus \\
\hline \multicolumn{3}{|l|}{ curve geometry } \\
\hline circle & circle & ellipse \\
\hline ellipse & ellipse & ellipse \\
\hline parabola & parabola & bs3_curve \\
\hline hyperbola & hyperbola & bs3_curve \\
\hline nurbs & $\begin{array}{l}\text { b_spline_curve / b_spline_curve_with_knots / } \\
\text { rational_b_spline_curve / uniform_curve / quasi_uniform_curve / } \\
\text { bezier_curve }\end{array}$ & bs3_curve \\
\hline offset curve & offset_curve_3d & bs3_curve \\
\hline line & line & straight \\
\hline \multicolumn{3}{|l|}{ linkages } \\
\hline PMI<->BREP & BREP<-geometric_item_specific_usage->shape_aspect<-PMI & spacollection / entity \\
\hline $\begin{array}{l}\text { PMI<->polyline } \\
\text { presentation }\end{array}$ & $\begin{array}{l}\text { PMI<-draughting_model_item_association- } \\
\text { >annotation_occurrence / draughting_callout }\end{array}$ & not covered \\
\hline
\end{tabular}


Appendix B.2: Mapping Other MBD-related Items into STEP and ACIS

\begin{tabular}{|l|l|l|}
\hline PMI & STEP AP242 & ACIS \\
\hline Notes & text_literal & not supported \\
\hline Flag Notes & not supported & attrib_spaxpmi_flagnote \\
\hline Surface Finish (roughness) & not supported & attrib_spaxpmi_roughness \\
\hline Tables & not supported & not supported \\
\hline Global or General Tolerances & not supported & not supported \\
\hline Views & draughting_model / camera_model & spaxpmi_capture \\
\hline
\end{tabular}


Investigating the Impact of Standards-Based Interoperability for Design to Manufacturing and Quality

Appendix C: Technology Readiness Levels (TRL) ${ }^{17}$

TRL 1: Lowest level of technology readiness. Scientific research begins to be translated into applied research and development (R\&D). Examples might include paper studies of a technology's basic properties.

TRL 2: Invention begins. Once basic principles are observed, practical applications can be invented. Applications are speculative, and there may be no proof or detailed analysis to support the assumptions. Examples are limited to analytic studies.

TRL 3: Active R\&D is initiated. This includes analytical studies and laboratory studies to physically validate the analytical predictions of separate elements of the technology. Examples include components that are not yet integrated or representative.

TRL 4: Basic technological components are integrated to establish that they will work together. This is relatively "low fidelity" compared with the eventual system. Examples include integration of "ad hoc" hardware in the laboratory.

TRL 5: Fidelity of breadboard technology increases significantly. The basic technological components are integrated with reasonably realistic supporting elements so they can be tested in a simulated environment. Examples include "high-fidelity" laboratory integration of components.

TRL 6: Representative model or prototype system, which is well beyond that of TRL 5, is tested in a relevant environment. Represents a major step up in a technology's demonstrated readiness. Examples include testing a prototype in a simulated operational environment.

TRL 7: Prototype near or at planned operational system. Represents a major step up from TRL 6 by requiring demonstration of an actual system prototype in an operational environment.

TRL 8: Technology has been proven to work in its final form and under expected conditions. In almost all cases, this TRL represents the end of true system development.

TRL 9: Actual application of the technology in its final form and under mission conditions, such as those encountered in operational test and evaluation (OT\&E).

\footnotetext{
${ }_{17}$ United States Department of Defense. (2011, April). Technology Readiness Assessment (TRA) Guidance. Retrieved from http://www.acq.osd.mil/chieftechnologist/publications/docs/TRA2011.pdf.
} 